\title{
Entre Tintín y Tartarín: la misión Dacar-Yibutí En el origen de la etnografía francesa ${ }^{1}$
}

\author{
F ernando G iobellina Brumana \\ Professor de A ntropologia Social - U niversidad de Cádiz
}

RESUMO : La Misión D akar-Y ibutí, bajo la conducción de Marcel Griaule, atravesó el continente africano entre 1931 y 1933. Este trabajo describe sus vínculos con la naciente etnografía francesa, así como la forma en la que se organizó y llevó a cabo.

PALABRAS-CLAVES: Etnografía francesa, D ogon, E tiopía.

A Inmaculada Díaz Narbona.

D onde termina el mapa del mundo, es donde empieza Tombuctú.

(Auster, 1999)

Al sur de Tombuctú - uno de los emblemas de la lejanía más extrema para la imaginación occidental-, poco más allá de los límites del Sahel, en el actual Malí, se extiende a lo largo de doscientos kilómetros el acantilado de Bandiagara, que en algunos puntos llega a los 600 metros de altura. Este acantilado divide tres zonas, una de meseta, otra de llanura y, mínimo hinterland, los escombros que durante milenios han ido cayendo de las abruptas paredes. Aquí, en una estrecha faja entre las tres zonas, hace cuatro o cinco siglos se establecieron los dogon, provenientes del Mandé, legendario país cuya ubicación aún hoy se discute. También la razón del éxodo varía según la fuente; tal vez la presión islamizante, tal vez un conflicto entre linajes². 
Fernando G iobellina Brumana. Entre Tintín y Tartarín: La misión D acar-Y ibutí

El enclave ocupado por los dogon, que tenía la ventaja de ser un escollo a la caballería de los guerreros peuhl, es un paisaje estremecedor, lo que, sumado a la arquitectura fantástica de sus aldeas - Roma lunar, Leiris dix it y también, que para entender estas casas había que pensar en Caligari (la película expresionista de Mabuse) y en Picasso -, al arte mostrado en sus máscaras, en sus puertas y cerraduras, en sus estatuillas - objetos todos vendidos hoy en tiendas especializadas de Nueva York, Madrid o Río de Janeiro ${ }^{3}$ - a la sabiduría metafísica que se les atribuye, ha dado a este grupo un peso a ojos europeos que no se corresponde con su importancia demográfica dentro de Malí, 460.000 sobre poco menos de 11 millones de habitantes (www.sil.org/ ethnologue/ countries/ Mali.html) ${ }^{4}$. Privilegio éste que ha sido reconocido y aumentado por la Unesco en 1989 al inscribir el país dogon como patrimonio de la Humanidad y otorgarle la denominación de Santuario Natural y Cultural del Acantilado de Bandiagara.

En los años 30, la población dogon no sumaba más de 200.000 habitantes. Supongo que la abundantísima literatura comenzada con la Misión D acar-Yibutí habrá convertido la tasa de páginas per nativo en la más alta de toda la historia de la etnología. Se ha escrito tanto sobre los dogon que hoy el tema atrae menos a los investigadores africanistas. Así, por ejemplo, ninguno de los once artículos que conforman un reciente número monográfico del Cahiers d' études africaines sobre Malí (n.144, Mélanges maliens), y ninguno de los diez libros allí reseñados se ocupan de este grupo, sino de vecinos suyos: peuhl, bambara, mandinga, fulbe, tuareg, así como de problemas generales como la alimentación, la condición urbana y rural, la posesión, etc ${ }^{5}$. Los dogon no están ya de moda, pero lo estuvieron, y tanto. No sólo por lo mucho que se publicó, sino también por qué se publicó, es decir, por el tipo de trabajo que se hizo. El supuesto descubrimiento de un "mensaje", de una "sabiduría alternativa", ha convertido a los dogon en fenómeno único; en ciertos círculos esotéricos se les concede reminiscencias de visitas de extraterrestres (Beaudoir, 1984: 9). 
Revista de Antropologia, São Paulo, USP, 2002, v. 45 nํㅡ.

Un atractivo tal ha llegado a convertir la región en lugar de destino de turismo de lujo, una suerte de reserva natural de insólitos nativos metafísicos. Más aún, este turismo es la principal herramienta para contrarrestar la migración de la población y el mantenimiento más 0 menos forzado de su cultura (Ciarcia, 1998: 107). Aunque quizá las cosas hayan ocurrido al revés, y los propios dogon sean producto del turismo.

Ante todo, y contra el mito que después se fraguó, de manera alguna éstos eran desconocido de los franceses pre-G riaule ${ }^{6}$. Además de libros de mayor o menor valía (D elafosse, D esplagnes, Seabrook), hay algo más significativo: el mismo año 1931 en que la Misión llegaba a Sanga, meses antes, un grupo de danza de máscaras se presentaba en el marco de la Exposición Colonial en París ${ }^{7}$, en una gran gala: 600 invitados, con un buffet que costó 8.500 francos (4.000 euros), y en la que además intervinieron acróbatas de la Costa de Marfil, bailarinas de Figuiri y de D ahomey. A los bailarines dogon se les daba el nombre que les atribuían los musulmanes peuhl: habé, es decir, en la lengua de aquéllos, 'infieles'. Y se había pensado en traer su espectáculo, porque las autoridades coloniales de Bandiagara acostumbraban a agasajar a los viajeros relevantes con la puesta en escena de estas danzas. D esde un comienzo los dogon, aún antes de ser conocidos por tal nombre, estuvieron vinculados al espectáculo.

De todas maneras, su publicitación por los trabajos de Griaule y su gente, las fotografías, las exposiciones, los filmes ${ }^{8}$, los libros, etc., son hoy el mito originario del descubrimiento de la sabiduría dogon: D ieu d'eau está en el bolsillo de todo guía turístico y las tiendas de souvenirs reclaman ser atendidas por nietos de 0 gotemmêli, el sabio, anciano y ciego - iqué griego resulta esto! - que había transmitido a $\mathrm{G}$ riaule los arcanos de la sabiduría de su pueblo. Los dogon juegan a ser dogon según un libreto establecido por académicos franceses.

La práctica antropológica que ha tenido este efecto está en el nacimiento de la etnología francesa; sin embargo, no ha surgido de aquí un paradigma vigente, ni se ha sentado un teoría explícita. La escuela Griaule se agotó prácticamente en sí misma, salvo quizás en un cierto 
eco en la obra de estudiosos de la religiosidad popular brasileña, en especial del Candomblé, gente como Bastide, Verger o Elbein, prolongada hasta la actualidad por nuevos investigadores, o, más que eco, una cierta sintonía común?.

\section{La etnología en el campo cultural francés}

Cualesquiera que sean las razones intra-disciplinarias que hagan digno de atención este episodio de la historia de la antropología y sus reverberaciones (el carácter colonial de esta práctica etnográfica; la relación entre antropología y poesía [Brumana, 2002], los objetivos y los medios de la disciplina, etc.), hay una, supra-disciplinaria, que opera como telón de fondo y que habla de los rasgos específicos adquiridos por la antropología francesa, y que nos abre a la interrogación sobre el papel de los antropólogos en su propia tribu, a una antropología de la antropología, por así decir. Como no ha ocurrido en ningún otro país, que yo sepa, en Francia la antropología ha sido uno de los ejes sobre los que se ha urdido el campo - no muy delimitado, por cierto - de la cultura erudita (y no tan erudita), esa red multireferencial que se convierte en el espacio de ocupación y preocupación de las elites; si entiendo bien, aquello a lo que Clifford (1995: 149) apunta con la expresión "orden cultural".

No se trata ya de éxitos editoriales como los que últimamente han tenido Marvin Harris o Carlos Castañeda, que antes tuvo Margaret Mead, y antes aún Frazer ${ }^{10}$, sino de algo mucho más articulado y firme: una interlocución y hasta una inter-producción y una retro-producción que ha estado en acto desde fines de los 20 y comienzos de los 30 . Sartre, Merleau-Ponty, Ricoeur, Althusser, D errida, D eleuze (y en la vecina Italia, Paci y Vattimo) tuvieron en la antropología un campo privilegiado de reflexión filosófica y en los antropólogos los primeros convidados a las páginas de sus libros; esto colocaba a la antropología como referente central de una filosofía, la francesa, que ha tenido este siglo papel clave en su cultura nacional. Pero no sólo filósofos. La presencia de cuestio- 
Revista de Antropologia, São Paulo, USP, 2002, v. 45 nํㅡ.

nes antropológicas en textos psicoanalíticos (Lacan, lacanianos, poslacanianos, paralacanianos, etc.) es central para el núcleo duro de sus desarrollos. Pero no sólo psicoanalistas, también lingüistas: Benveniste, Todorov, Kristeva, D ucrot... - además del obvio Jacobson, que hizo amistad con Lévi-Strauss en Nueva Y ork en la primera mitad de los años 40 -. En síntesis, una espesa red que supera el plano universitario para alcanzar el de las artes y, más en general, un espacio público. Aquello a lo que aludo se ejemplifica en que la inauguración en 1938 del Museo del Hombre fuese celebrada con una cantata compuesta por D arius Milhaud sobre palabras de Robert D esnos, o que a Leiris, camino de Etiopía, le llegase carta de su cuñado, uno de los principales galeristas parisinos, relatando con entusiasmo la visita al estudio de Picasso y qué cuadros nuevos había encontrado, o que Lévi-Strauss haya usado como una de las ilustraciones de L a pensée sauvage un objeto "exótico" comprado a Lacan cuando éste padeció dificultades económicas debidas a su separación de la ex-mujer de Bataille... 0 , en forma más explícita, que en los años 60 una tendencia antropológica, el estructuralismo, se haya hecho moda extradisciplinaria.

La Misión D acar-Yibutí, con su poeta que acababa de romper con Breton en el cargo de archivista, es, pienso, el acontecimiento en el que se plasmó este espíritu colectivo desde el ángulo etnológico. La etnología francesa nacía tardíamente pero generaba y regeneraba diversas fuentes de producción cultural, de las que era a su vez generada. Este proceso se canalizó por diversos medios más o menos institucionalizados; uno de ellos, no el menos importante, fue el de las publicaciones eruditas generalistas en las que Francia tiene una amplia trayectoria.

Se ha hablado mucho del papel que en este sentido habría desempeñado la revista D ocuments - reeditada hace poco en edición facsímil con introducción de D enis Hollier -, dirigida por Bataille y en cuya fundación Rivière (1987: X n. 3) tuvo el papel esencial de encontrar al mecenas que hiciera posible la aventura ${ }^{11}$; Clifford (1995 [1981]) le otorga un peso que estudios posteriores consideran excesivo ${ }^{12}$; la 
etnología en ella, más que una realidad, era un desideratum a ser realizado. D atos: sobre alrededor de 1.000 páginas que en su totalidad publicó la revista, sólo 30 eran de carácter etnográfico (Jamin, 1999: 265) y varios de los autores de tales trabajos (Frobenius, Nordenskiöld, von Sydow) nada tenían que ver con el futuro desarrollo de la antropología en Francia.

Q uienes sí iban a tener que ver (G riaule, Rivière, Leiris, Schaeffner), aportaron contribuciones de poco calado, como si aún estuviese en estado embrionario lo que se desarrollaría a partir de 1931 (cuando ya la revista había desaparecido) ${ }^{13}$. La importancia de D ocuments en el nacimiento de la etnología francesa fue la de ser ámbito de encuentro, conocimiento y reconocimiento de varios de los participantes de la Misión D acar-Yibutí; hasta ámbito físico, ya que Leiris y G riaule se vieron por primera vez en las oficinas de la redacción de la revista. Pienso que, al mismo tiempo, la revista marcó la ausencia de algo que debía ser hecho, lo que sus cachorros de etnólogos iban a hacer.

Es curioso que no hubiese un heredero inmediato de D ocuments. Los primeros números de Minotaure, la bella revista editada por Albert Skira con gran lujo (hay reedición facsímil en 1981), hicieron pensar que se convertiría en el lugar de encuentro de la vanguardia literaria (más que nada, los surrealistas con Breton a la cabeza), la vanguardia de artes plásticas (Picasso - que ilustró la cubierta del primer número - , Miró - que ilustró otra portada -, Tanguy, Giacometti, Balthus, Man Ray, etc.), y las vanguardias de diversas áreas de las "ciencias del hombre", para decirlo de alguna manera.

La primera entrega traía algunas páginas de lo que sería L 'A frique Fantôme - las dedicadas a las danzas de las máscaras dogon - , además de un breve texto de Jacques Lacan ("Le problème du style et les formes paranoïaques de l'experience", que, al menos en título, casaba a la perfección con el texto de $\mathrm{D}$ alí al que sucedía en la paginación: "Nouvelles considérations générales sur le mécanisme du phénomène paranoïaque du point de vue surréaliste"). La segunda entrega, aparecida en la misma fecha que la primera, era un monográfico dedica- 
Revista de Antropologia, São Paulo, USP, 2002, v. 45 nํㅡ.

do a la Misión D acar-Y ibutí, que compilaba varios textos de Leiris, con un par de Griaule, y contribuciones de Lifchitz, Luten y Schaeffner, bajo una breve introducción firmada por Rivet ${ }^{14} \mathrm{y}$ Rivière. En la tercera, otro trabajo de Lacan analizaba el asesinato múltiple cometido por las hermanas Papin ${ }^{15}$. Y nada más. A partir del número 4 hasta el 12-13 de hecho, el noveno, ya que varios habían sido dobles -, M inotaure se limitó al papel de revista literaria y de artes plásticas sin más.

D espués de la guerra, desde octubre del 1945, la revista fundada por Sartre, L es Temps Modernes, en cuyo comité de redacción estaba primero Leiris y más tarde Pouillon, y en la que publicarían, además de ellos dos, Metraux, Lévi-Strauss, Clastres, Monod, Copans, Sebag, Jaulin, Balandier, Bourdieu, Condominas, entre los franceses, G . D evereux, M. Mead, R. Benedict, K. Gough, entre los americanos, abordaba la construcción de un espacio de reflexión y producción en el que la etnología tenía un papel privilegiado.

Este vínculo es correlativo, pienso, a que para una visión exterior a la dinámica francesa, la de Edmund Leach (1972: 21), las argumentaciones de Lévi-Strauss tuviesen "un trasfondo existencialista"16; la indistinción en la que el antropólogo británico confundía perspectivas que en Francia parecían tan opuestas provenía de una lectura de la producción de la escuela del A nnée Sociologique que dejaba de lado la cuestión de "significación y sociedad", lectura característica de la tradición británica. Cuando ésta asomaba, les resultaba demasiado exótica, "existencialista", aunque fuesen autores como Needham, EvansPritchard, Fortes, Gluckman, entre otros, los que desde fines de los 50 redescubrieran los en Francia semi-olvidados Hertz y Van Gennep o textos incómodos como el de D urkheim y Mauss sobre clasificaciones. Pero, ¿en qué consiste esta cuestión, tal como estaba planteada en la escuela francesa, y que puede ser vista-por cierto, no sin razón- como existencialista? Que la sociedad, como la significación, está basada en nada ${ }^{17}$.

Una calificación del mismo orden de extrañeza es la que Clifford (1995 [1981]) propuso para la etnología francesa de los 30: "antropología 
surrealista". En este caso, sin embargo, tal hallazgo no parece indicar más que una oportuna - u oportunista - aproximación periodística. Como he sostenido en otro lugar (Giobellina Brumana, 2001), es exactamente la ruptura definitiva con el surrealismo lo que permite a Leiris acceder a la etnografía. Según alguien que ha intervenido en esta polémica recientemente, el enfrentamiento etnografía/ surrealismo se hacía patente en la propia relación que una y otra establecían con los objetos otros llevados a los museos. Mientras que la intención etnográfica era la de revivir el contexto a partir de las muestras obtenidas, los surrealistas "practicaban una descontextualización de los objetos, prácticas y signos, apartándolos de sus funciones y usos" (Massonet, 1997: 105).

He dejado para lo último un hecho que tal vez muestre de manera más emblemática el carácter de vanguardia cultural de la etnología francesa en esos tiempos y el tipo de persona que eran sus cuadros: uno de los primeros grupos de la resistencia anti-nazi nació en el Museo del Hombre (Blumenson, 1979; Fabre, 1997), lo que llevó al fusilamiento de varios de sus miembros (sin contar la muerte en Auschwitz de la judía polaca nacionalizada francesa D eborah Lifchitz - arrestada en casa de Leiris -). En efecto, poco después de la ocupación de París, la bibliotecaria del Museo, Yvonne Oddon, junto a su compañero, el emigrado ruso Boris Vildé - lingüista dedicado a los países árticos - y su, compatriota Anatole Lewinski - especialista en chamanismo siberiano - , organizaron una celula de resistencia anti-nazi, tal vez la primera. Contaron para ello con la colaboración - además de la de Rivet, que pronto se exilió en Colombia - de otros trabajadores del museo, entre los cuales quizás la figura más destacada haya sido la de G ermaine Tillion, muy jóven en la época y recién iniciada en la práctica etnográfica con una estancia en Argelia junto a Thèrese Rivière - la hermana de George Henri -, pero sería injusto olvidar a Jacqueline Bordelet, René Creston y Marie-Louise Joubier. Esta célula realizó diversas tareas de contrapropaganda, ayuda a la evasión de prisioneros y de 
perseguidos por los invasores o las autoridades colaboracionistas, y publicó el primer periódico de la resistencia con precisamente ese nombre Résistanœ - que se convertiría en el sinónimo de la lucha anti-nazi.

Es verdad que antropólogos de otras nacionalidades fueron al combate, los ingleses, para no ir más lejos: son evidentes los casos de Leach en Birmania contra los japoneses y Evans-Pritchard en Sudan contra los italianos ${ }^{18}$. Pero lo hicieron como oficiales británicos, al mando de tropas irregulares indígenas: su accionar habla de las sociedades en las que habían trabajado y, sin duda alguna, de su inserción en ellas, no de su papel en la cultura inglesa.

¿Sirvió este estado de apertura de la antropología francesa a una sensibilización mayor de la ciudadanía frente a fenómenos como los movimientos independentistas posteriores a la guerra? No; y fue un antropólogo, Jacques Soustelle, alumno dilecto de Mauss, quien, como gobernador General de Argelia estuvo a cargo de uno de los momentos más duros de la represión anti-FLN. ¿Sirvió al menos para que diese una flexibilización mayor a sus textos, una capacidad de representación más diáfana de aquello que estudiaba? Tampoco, al menos en opinión de Leiris de que justamente la proximidad con la literatura obligaba a los antropólogos a una "cientifización" que volvía sus escritos más secos y menos atractivos ${ }^{19}$. En el prólogo a la segunda edición de L e vaudou haïtien, documento desencantado y dolido por el suicidio de su amigo Metraux, dice:

Los investigadores, con pocas excepciones, confunden objetividad científica y actitud de rechazo respecto a lo relativo a su propia personalidad y, al mismo tiempo, de distanciamiento de la aventura intelectual y material, su investigación, cuyos aspectos circunstanciales, sin embargo, no pueden ser dejados en un segundo plano porque en otras condiciones o con otro protagonista hubiese sido diferente (o ni siquiera hubiese sido). Si se piensa - y es mi caso - que una etnología de tal manera desencarnada erra su finalidad ya que no brinda más que secos diagramas de las sociedades consideradas, y no retratos en los que sus particularidades culturales, tal como quien las describe las han aprehendido, son hechos los suficientemente sensibles como para que se pueda tener la ilusión de vivirlos, se tiene que preferir la etnología 
en cierta forma artesanal que ha practicado Metraux a la que es producto del espíritu fríamente científico y que tiende a poner entre paréntesis a ese investigador sin cuyo ojo y sin cuya mano las investigacines no tendrían ninguna existencia palpable. (Leiris, 1968: 8)

El proceso al que me he referido permitió percibir, en algún caso, la familiaridad entre poesía y etnología. Ambas, en efecto, tienen una capacidad similar de hacer patente la realidad humana, de disolver ilusiones al mismo tiempo que recoger todo el valor de ese carácter mítico, de revelar verdad. En ese sentido, la etnología es carnavalizante. Pero todo carnaval tiene su cuaresma: la etnología se torna institución, la levedad pesantez, la libertad sujeción.

\section{El ingreso en la modernidad}

A comienzos de la década de los 30, la etnografía francesa estaba aún por nacer. Mauss era quizás quien con más intensidad echaba en falta su existencia, quien con más intensidad se quejaba de la incapacidad francesa de ocupar en este terreno un nivel semejante al obtenido en otros campos disciplinarios y al alcanzado por los etnólogos de otros países; ingleses, americanos, alemanes, hasta los suecos carentes de dominios coloniales, mostraban una productividad extraordinaria. "Chez nous" - se lamentaba en 1913 - "c'est le néant", por más que "nuestras colonias están surcadas por las expediciones etnográficas extranjeras" (Mauss, 1969 [1913]: 412). Lo que los franceses tenían en su haber era "una literatura colonial tan abundante cuanto efímera, cuya bibliografía es tan larga cuanto su substancia es pobre" (: 406).

Frente a la vorágine entrópica de lo que hoy llamamos "globalización" ("No se puede esperar para observar [...] civilizaciones que van a ceder al contagio de nuestra uniforme cultura occidental" 20 [: 432]), hasta por un simple "egoísmo de coleccionistas", surgía la exigencia:

¿No se deberían observar esas sociedades secretas, esas "clases de edad", esas corporaciones de sacerdotes y de magos, de bardos y de adivinos que 
Revista de Antropologia, São Paulo, USP, 2002, v. 45 noㅡ.

pululan en todas esas pequeñas y grandes tribus negras, y con las que precisamente nos las hemos tenido que ver en los recientes incidentes de Bandiagara ${ }^{21}$ ? A un por curiosidad literaria, estaría bien penetrar en el alma de esas gentes. (:407)

Sin embargo, nada se hizo, nada se pudo hacer. Siete años después, cuando Mauss (1969 [1920]: 434) volvió a hacer un panorama de la antropología francesa, la situación era aún peor: la guerra había segado buena parte de aquellos que hubieran podido llevar a cabo las tareas que Mauss veía como indispensables y la ampliación del imperio francés había extendido el campo de estudios. La raíz del problema era la falta de inversiones públicas en la creación de museos etnográficos, centros de investigación y de formación de personal ${ }^{22}$. Un abandono tal se debía, a su vez, a que "el gran público ignora todo sobre nuestras investigaciones" ${ }^{23}$. En la discusión que siguió a la presentación de Mauss, su amigo Rivet proponía hacer en antropología lo que se había hecho en astronomía, la creación de un mito popular y popularizador ${ }^{24}$ : "il faudrait un Flammarion à l'anthropologie" (: 435).

Y el Flammarion etnológico surgió a bombo y platillo: era Marcel Griaule y su expedición entre el Atlántico y el Mar Rojo por tierras africanas. Este salto venía a coronar, al mismo tiempo que a apuntalar, una serie de rápidos progresos en la posición institucional de la etnología francesa a partir de fines de los años 20 (la fundación en el marco la Sorbona del Instituto de Etnología, el nombramiento de Mauss en el Collège de France, el de Rivet a la cabeza del Museo de Etnografía del Trocadero y su integración en el Museo de Historia Natural), favorecida por el avance electoral de la izquierda que desembocó en el triunfo del Frente Popular en 1936. La etnología, progresista y antiracista, tomaba así la delantera a la antropología reaccionaria y racista de la Escuela de Antropología de París y la Sociedad de E tnografía. Pocos años después, con la ocupación y el gobierno colaboracionista de Vichy, esta ventaja se invertiría, aunque no queda del todo claro de que parte estuvieron algunos de los forjadores de la Mission (Fabre, 1997). Pero por de pronto, 
era la hora de los herederos de L 'A nnée Sociologique, y el Museo - el del Trocadero primero y más tarde el del Hombre - era su nave insignia ${ }^{25}$.

Se planteaba una cuestión de imagen, correlativa a la marginalidad que hasta entonces tenía la etnología, imagen que, en manos de Rivet y más que nada de su segundo de abordo del Museo, Rivière, iba a ser desempolvada y modernizada. Como se lee en un comunicado de prensa, el primero, creo, de los tantos con que las nuevas autoridades del Museo bombardearían los periódicos: "Inauguración del vestíbulo de entrada. El gran vestíbulo de entrada era hasta ahora obscuro y mal dispuesto" (27-VI-1930) ${ }^{26}$. Las novedades: luz eléctrica, eliminación de piezas inútiles, instalación de la enorme cabeza de la Isla de Pascua (traída por Pierre Loti, el más emblemático de los escritores viajeros coloniales; ahora está en el Louvre esperando la apertura del Museo Branly). Al mismo tiempo, recepción del tótem que aún hoy está en la puerta del Palais Chaillot - y que da nombre a su restaurante - , donación de la Compañía de Ferrocarriles del Canadá.

Unos meses después, una exposición - Peaux-rouges d'hier et d'aujord'hui - para cuya inauguración, la máquina propagandística que poco después trabajaría para la Misión ya se mostraba operativa: comunicados de prensa, invitados bien escogidos, excelente cartelería y folleto explicativo. Lo menos destacable era la propia exposición, 0 mejor, el equipo que había recolectado las piezas que la componían: la Mission Paul Colze, un grupo de cinco scouts que fue a "estudiar los últimos indios del Canadá" entre junio y octubre de 1930, con el fin de "recoger documentos y objetos para el Museo, rodar un documental, grabar discos con cantos indios, registrar sus costumbres, su higiene, el trabajo de asimilación realizado por el gobierno canadiense" (tomado del folleto). Se exhibían fotos, cuadros pintados por Colze, registros de "manchas mongólicas", mechas de pelo de hombres y mujeres, estatuillas (de un cazador indio y de un trampero del XVII), maquetas de tipi además de un tipi adornado con pinturas rituales, y todos los objetos indígenas imaginables: ropajes, tiaras de plumas, calzados, arcos y flechas, 
Revista de Antropologia, São Paulo, USP, 2002, v. 45 nํㅡ.

trineos, etc. Para el regocijo futuro, la foto de los exploradores: cinco señores adultos en uniforme scout, apoyados en sus bastones de marcha, hombro con hombro como si fuesen un conjunto musical, junto al jefe indio yakima Os-Ko-Mon, erguido y en pose, con todo su plumaje y una manta en el brazo, a la puerta de un tipi; parece el sueño hecho realidad de Guillermo, el personaje de los libros infantiles de Richmal Cromton. No era ese el medio más oportuno para encender el entusiasmo público.

La imagen que unía modernidad con azaña, con exotismo, con aventura, con sacrificio, con conquista, todo bajo la causa de servicio al imperio francés, la daba muy bien algo que la Citroën había puesto en marcha en África un par de veces, las "croisières", con equipamiento técnico novedoso, con abundante personal comprometido, con muchos riesgos, con importantes trabajos de intendencia, con metas que llenaban la imaginación y que beneficiaban, al menos simbólicamente, al funcionamiento de la administración colonial: cruzar el Sahara uniendo Argelia con el Africa O ccidental Francesa -, cruzar África uniendo las colonias del continente con la aislada Madagascar ("Partout, ils rencontreront un accueil délirant" [www.citroen.com/ site/ html/ histoire]). Era esto lo que vehiculos provistos de orugas habían realizado; entre diciembre de 1922 y marzo de 1923 en el primer caso; entre octubre de 1924 y abril de 1925, la segunda. Una tercera "croisière" se superpuso en el tiempo a la Mission; días antes de la salida del navío St. Firmin hacia D akar con G riaule \& Co, partía otra expedición Citroën, esta vez para el Asia central, la Croisière Jaune que iría a recorrer "30.000 kilómetros para unir Beiruth a Pekin, pasando por el Turkestan ruso, Sinkiang, el desierto de Gobi hasta el río amarillo" (ídem).

Con este modelo de raid deportivo, la Misión D acar-Y ibutí estaba, en muchos sentidos, más próxima a la actual Paris-D acar que al trabajo de un Maurice Leenhardt, vuelto hacía poco a la Metrópolis tras una estancia de un cuarto de siglo entre los canacos de Nueva Caledonia, desconocido por el gran público anecdótico y novelero del que hablaba Mauss. Era un hecho social, no tanto en el sentido 
Fernando G iobellina Brumana. Entre Tintín y Tartarín: La misión D acar-Y ibutí

durkheimiano (aunque también, si se piensa un poco), sino más bien en el del de la crónica rosa.

\section{La puesta en marcha de la Mission}

Jean Jamin, compilador y prologuista de la edición de textos africanos de Leiris (1996), deplora la "publicidad arrogante" que desde el primer momento rodeó a la misión; en efecto, ¿cuándo, antes o después, las primeras páginas de los periódicos se habían hecho eco de un acontecimiento antropológico? No se trataba sólo de la prensa de Paris y de las principales ciudades de Francia, sino de la de Marruecos, Argelia, España, Italia, el Times de Londres, el Christian Science Monitor de Boston, el Chicago Tribune, el N ew Y ork H erald y hasta L e courrier d'Ê thiopie, de Addis Abbaba. Para nada es éste un hecho secundario o anecdótico, sino un elemento clave de cómo fue programada la Misión de cara al público al que se apelaba a través de los medios de comunicación como nunca se había hecho ni se volvería a hacer en la historia de la antropología. Esta relación fue cuidada con minuciosidad y rigor, tanto antes del comienzo de la expedición como durante su desarrollo, y lo central de esta empresa propagandística recayó sobre Rivière. En carta de éste a Griaule (31-X-31), ya en campo, con temor ante un cambio de presupuesto nacional que retirase los fondos ya otorgados por ley (la crisis económica del 30 estaba en su punto más caliente) encontramos una formulación explícita del acuerdo implícito, el do ut des, que basaba la buena relación entre etnógrafos y periodistas, exotismos por opinión pública:

En relación ala publicidad de la Misión en la prensa, se lafacilitaría mucho si, como ya te he dicho, dispusieramos de vez en cuando de alguna foto [tipo explorador, dice en otra carta - 30.9.31 - ] que daríamos como carnaza a los periodistas que incesantemente las reclaman y a quienes, por cierto, niego vuestras magníficas fotos técnicas. Tengo miedo de a la larga malquistarme con ellos, necesitamos a esta gente que nos han sido útiles, como recuerdas. 
Revista de Antropologia, São Paulo, USP, 2002, v. 45 nํㅡ.

La prensa se volcó en la Mission y le brindó una difusión enorme; de tal circunstancia surgió el éxito popular de la Misión. Entre los agradecimientos de Rivière a sus distintos mecenas encontramos uno dirigido a la señora Crucifix por la donación de tres botellas de un vermut que llevaba su nombre y otro a un comerciante por la de una caja de carne en gelatina. Más allá de la anécdota, estos detalles muestran la amplitud de la base de sustentación social de la Misión, hasta dónde había ésta entrado en el imaginario popular.

Era bien merecido, pues, el banquete que los expedicionarios ofrecieron a los periodistas días antes de su partida, que terminó en discursos de Rivière y G riaule; días después dieron otra comida, esta vez para la prensa anglo-americana, en la que sólo habló Rivière, que tenía buen dominio del inglès. Pero, como hemos visto en la carta de Rivière a $\mathrm{G}$ riaule, el vínculo con los periódicos no terminó con la partida de la Misión. Éstos recibían regularmente comunicados sobre la marcha de la misión enviados por Rivière - como los había mandado desde octubre de 1930, cuando se pensó en llevar a cabo la misión - , que también los mandaba, con ayuda de la mujer de Griaule, a todos los patrocinadores y a los diputados y senadores, a representantes ante la Sociedad de las Naciones, a la Rockefeller Foundation, etc. Las noticias de los periódicos son lo suficientemente similares como para que trasluzca el comunicado de prensa que se les había enviado ${ }^{27}$, igual que la foto de Griaule aparecida en decenas de periódicos, unas cuantas copias de la cual todavía están en las cajas de los archivos.

“¿Quién dice que el Museo Etnográfico del Trocadero era el sitio más polvoriento y vetusto de París? Antes, quizás, pero ahora el modernismo se ha instalado en los viejos pabellones. [... ] el director (sic), el Sr. Rivière, hombre joven, activo de espíritu, se revela un experto en ciencia-pugilística". Así comenzaba un artículo en el Paris-Midi (20X I-30) en el que se anunciaba algo que terminaba de dar a la Misión un cierto aire circense: un mes antes de la salida de los expedicionarios se celebraría en el Cirque d'H iver de París una gala boxística para recaudar 
fondos a su favor, con un combate entre el campeón mundial de peso gallo del momento, un panameño negro, naturalizado estadounidense, que respondía al nombre romántico y sonoro de Panama A l Brown, y el campión francés, Roger Simendé - al que noqueó en el tercer round - , además de tres peleas más.

Tal vez en este combate y en la propia figura del generoso boxeador se condensasen las paradojas, los contrasentidos, las ironías que rodearon el proyecto. Un negro luchando para que sus raíces fuesen al fin reconocidas en todo su esplendor, con el fin de que el dominio colonial fuese menos brutal y más racional, ese era el contenido simbólico que $\mathrm{G}$ riaule explícitamente veía, o pretendía que se viese, en el acontecimiento ${ }^{28}$. Pero, lejos de tal imagen, Panama Brown era un negro muy poco negro (sólo de piel, dice Jamin); es decir, alguien que por su origen nacional, su trayectoria vital, sus gustos, su aceptación social, hasta por su propio aspecto, nada tenía que ver con aquellos a quienes la misión iría a rescatar para la civilización. La fotografía que de él nos presenta Jamin, rodeado de los en verdad inmediatos beneficiarios de su match (G riaule, Rivière, etc.), es reveladora: un dandy muy guapo, estilizado y à la page junto a un pequeño grupo de poco agraciados sabios. Poco agraciados, pero supongo que agradecidos; la velada boxística había rendido algo más de de 100.000 francos (equivalentes a 45.000 euros).

Eran esos contrasentidos los que daban sabor, sabor de moderni-dad, y convertían en noticia a la Misión y a lo que estaba detrás suyo: el museo y los estudios etnológico. "El box al servicio de la ciencia", titulaban los periódicos, "El box al servicio de la causa colonial", mientras algunos editorialistas se quejaban de que un boxeador ganase fortunas mientras que la investigación científica y los propios científicos estaban en la ruina. $O$ tra de estas aparentes paradojas tam-bién señalada por la prensa: la donación de R. Roussel - "el artista más extravagante" - de 10.000 francos (4.500 euros) - a la Misión. "Science, poesie, aventure", era el titular de C omoedia (14-II-31). 
Revista de Antropologia, São Paulo, USP, 2002, v. 45 nํㅡ.

Hubo también un escándalo, que permitió a algún periódico destacar el alto riesgo que irían a correr los expedicionarios. En la primera estancia de $\mathrm{G}$ riaule en Etiopía había ocurrido un incidente muy confuso con una copa de oro enviada por su protector, el señor feudal de G odjam - el ras Haylou - , de quien tendré que hablar más adelante, a Raymond Poincaré, entonces presidente de la República Francesa. El orfebre no había terminado su trabajo en la fecha en que $\mathrm{G}$ riaule salía de la provincia, se le debía, pues, entregar en Addis Ababa antes de que partiese de Etiopía. A hora bien, la copa que llegó a manos de $\mathrm{G}$ riaule no era de oro, sino de plata barata pintada. Un escritor-viajero, André Armandy, que había estado por esas fechas en Etiopía, publicó un libro en el que contaba la historia, según él con una versión dada por $\mathrm{G}$ riaule, por la que el emperador Hayle Selasie aparecía como responsable del cambio de copas. El Emperador, informaba el periódico tomando el dato del propio Griaule, "ha llegado a prevenir a la representación de Francia de que si el Sr. M. G riaule volviese a la región de $\mathrm{G}$ odjam en la que ocurrieron estos acontecimientos, sufriría los problemas más graves, lo que en buen francés significa que será simplemente masacrado" (C omoedia, 17-X-30). Varios números de la publicación trajeron declaraciones y contra-declaraciones del escritor, del embajador etíope - que anunciaba una acción judicial contra éste por millones de francos - , de Griaule, enmarañando por completo la historia pero dando la última palabra, como no podía ser menos, correspondió a Griaule, vituperando a Armandy: "Un hombre que acaba de sabotear, por una parte, la influencia de Francia en Etiopía, y, por la otra, el trabajo de los investigadores serios" (C omoedia, 14-XI-30). Quien dictaba estas palabras a la prensa no sabía que poco tiempo después dirían lo mismo de él.

El último espectáculo brindado por la Misión días antes de su partida fue la exposición durante cinco días del material de la expedición, que llegaba a las nueve toneladas: coches, camiones, barco, cinco tiendas de campaña, un grupo electrógeno, una ametralladora, varios fusiles y revól- 
veres, aparatos de cine y de foto, cajas de champagne, de cognac, de conservas. La mayoría de los periódicos dieron la noticia según el comunicado que les había llegado; otro, más entusiasta, tuvo su propia crónica, en un tono que hubiera acongojado al Lévi-Strauss de "odio los viajes":

Esta visita constituye una irresistible invitación al viaje. La ciudadela de las cinco tiendas se compone de: un cuarto-dormitorio, una secretaría-oficina de trabajo con mesa plegable y archivos metálicos; después, la sala de música y grabación, el estudio fotográfico y cinematográfico, y, para terminar, la cocina de chapa metálica y la sala de duchas de caucho. Bajo las tiendas, camas metálicas provistas de mosquiteros de velo de primera comunión invitan a la siesta. [... ]Y la bandera francesa ondea alegremente sobre los coches, bajo el cielo de mayo, cargado de las más bellas promesas. (A nnales coloniales, 2-5-31)

Un espectáculo que no fue: un documental sonoro que Rivière estuvo negociando con la productora Paramount, pero sin resultado positivo. D ías antes de la partida de la Misión, sin embargo, Rivière escribía para una revista de información general, Pour $\mathrm{V}$ ous, un comentario sobre un documental - L'A frique vous parle - producto de una expedición estadounidense, dirigida por Paul Hoefler y Walter Futter, que había recorrido $14.000 \mathrm{~km}$ de Lagos - en el Atlántico - a Mombassa - en el Pacífico - pasando por Tchad, el Africa Ecuatorial Francesa, el Congo Belga, etc. "Hacen amar a los primitivos amándolos ellos mismos", dice Rivière, para terminar con una referencia a la Misión que "se enorgullecerá de presentar dentro de dos años, una película tan apasionante como L 'A frique vous parle". No parece que esta expresión de deseos haya sido más que un recurso retórico. Por más que uno de los miembros del equipo $\mathrm{G}$ riaule tenía alguna competencia cinematográfica y la ejerció, habría que esperar más de una década para que con Jean Rouch se cumpliese ese objetivo.

$* * *$

Los dineros oficiales llegaron con el viento a favor de la opinión pública y por la vía más alta imaginable. La propia A samblea Nacional, 
con la unanimidad de todos los grupos parlamentarios, a propuesta del Ministro de Educación y con el apoyo del jefe del gabinete del Ministro de Colonias, establecía la creación de la M isión etnográfica y lingüística D acar-Y ibuti2 ${ }^{29}$. El campo de maniobra de la Misión era, sin embargo, más amplio. Como dicen Rivet y Riviére (1933: 3-5) en su introducción al monográfico de M inotaure dedicado a la cuestión, los expedicionarios tenían en su haber, además de la recolección etnográfica de 3.500 objetos y las anotaciones lingüísticas "de 30 lenguas o dialectos en su mayoría desconocidos hasta hoy", la obtención de una gran colección de pinturas, amuletos (de hecho, rollos de pergamino con escritos "mágicos"; cf. Lifchitz, 1933) y manuscritos etíopes, animales disecados, y la realización de "investigaciones arqueológicas, topográficas, antropológicas [en el sentido físico, se entiende] ${ }^{30}$, entomológicas, embriológicas, botánicas, etc." , hasta algún animal vivo para el Jardin de Plantes.

La ley aprobada, con fecha del 31-III-31, dotaba a la Misión con 700.000 francos (316.000 euros) $)^{31}$, de los cuales 400.000 francos (180.000 euros) fueron incorporados a ese ejercicio y el resto se comprometía para el siguiente. Las contribuciones de otras instancias públicas (administraciones coloniales, instancias académicas) y privadas (empresas comerciales, fundaciones, individuos) fueron, según se lee en el proyecto de ley, de 300.000 francos (136.000 euros). Se movilizaron, pues, fuerzas de muy diversa naturaleza: el Estado Francés, sponsors bancarios y comerciales ${ }^{32}$, fundaciones, "personalidades" ${ }^{33}$.

Y seguirían siendo movilizadas durante el tiempo que la Misión estaba ya en África, puesto que absorbía mucho dinero. En carta del 22-II32, G riaule reclamaba a Rivière :

Te recuerdo que aquí vivimos 15 hombre y 3 coches, quenosotros mismos fabricamos nuestra electricidad y nuestro hielo para las fotos; que debemos asegurar nuestro transporte (cada mes hacemos varios miles de quilómetros); que hasta ahora tenemos 1500 objetos que no piden otra cosa que reproducirse. 
El esfuerzo recaudador tuvo que redoblarse cuando la mala situación de la economía hizo que los apoyos disminuyeran ("D esgraciadamente, nuestros esfuerzos se ven trabados por la crisis general. Los donantes, salvo los inagotables D avid-Weil y Charles de Noailles, han cesado por completo su ayuda; las Colonias han reducido sus subvenciones [al Museo] de 150.000 a 50.000 francos", comunica Rivière a G riaule carta del 22-VII-32 -. Pero el terreno estaba bien abonado.

\section{El África de la Mission}

Lo negro era moda en París, pero una moda tal sólo era factible por el malentendido. Negritud espectáculo, negritud desenraizada, negritud bastarda; Joséphine Baker, la mulata de Nueva O rleans que hizo furor en Francia desde mediados de los años 20, es quizás la mejor muestra de ese encanto y la mejor muestra de la ficción sobre la que éste se montaba ("domesticaba el exotismo", dice Jamin).

El jazz, triunfante en París tras el éxito del tango, aparecía como música negra, cuando, en verdad, sobre sus indudables bases rítmicas de origen africano, había construido, absorbiendo todo tipo de influencia europea, un arte occidental ${ }^{34}$. Lo que excitaba del jazz, lo que antes había excitado del tango, era su origen marginal, su nacimiento en los arrabales, en los prostíbulos (hay que notar por otra parte que el tango también tiene raíces afro, como el samba que llegaría a París mucho más tarde); algunos de los historiadores del jazz dicen que el término en un comienzo significaba un coito rápido, hecho a escondidas en lugar público. Este gusto por el jazz no era algo ajeno a la práctica etnológica, al menos en el caso de algunos de las figuras de la Misión, como Leiris. Seité (1999) muestra que el jazz tuvo para la vida y la obra de éste, en su propio estilo literario, una importancia estratégica ${ }^{35}$.

El arte negro, las máscaras ante todo, había fascinado pocos años antes a galeristas y artistas plásticos parisienses; a diferencia de lo que ocurría con los surrealistas, más sensibilizado por las artes de 0 ceanía, 
los cubistas - el caso de Picasso, el más evidente - sufrireron mucho su influencia ${ }^{36}$. África, mediada y cubierta de prestigio para el gran público por su apropiación y reelaboración por parte de las elites, sensualizada por el jazz y las estilizadas danzas de la Revue nègre, tenía un atractivo del que carecían otras posesiones francesas de ultramar. Hubo, sin embargo, a quien le horrorizase esa moda; nada más y nada menos que Salvador Dalí. Recordaría décadas más tarde, en 1971, a toro pasado y quizás con su ansia de destacar como enfant terrible:

Encontre los pisos de la gente más respetable, más refinada, gente de mundo, artistas, como Picaso, en una palabra, en los pisos de aquellos a quienes yo más respetaba, invadidos por una avalancha de horribles esculturas salvajes [...], esos objetos etnológicos que más detesto en el mundo y tan feas como pecados mortales [...]. No hay que llamar a eso arte; es un producto miserable del miedo de los salvajes. Y un salvaje es lo peor que hay en el mundo" (apud Hugier, 1990: 52).

\section{$* * *$}

D escubrir los tesoros culturales africanos y a partir de ello, legitimar la práctica etnográfica: esa era la gran jugada a la que apostaron quienes promovieron el viaje de Griauley sus compañeros. En otro texto (Giobellina Brumana, 2002) he discutido sobre esos tesoros y sus instrumentos de su captura. El marco global en el que la aventura se inscribía era el de la edad de oro del poder colonial francés; la Exposición Colonial de 1931 en el Bois de Vincennes, en la que intervinieron varios etnólogos como Maurice Leenhardt (Fournier, 1994: 612), y en la que se exhibieron, como ya he dicho, los bailes de máscaras dogon, tuvo un éxito de público abrumador.

El carácter colonial de la Misión D acar-Yibutí es y era evidente. A nadie llamaba la atención que así fuese, era el sentido común de la época, impugnado quizás sólo por los surrealistas, aunque no tanto por una opción política, sino más bien por su actitud subversiva general dentro de la que el antipatriotismo extremo formaba parte del cuadro; el 
Fernando G iobellina Brumana. Entre Tintín y Tartarín: La misión D acar-Y ibutí

anticolonialismo no era, al menos en un comienzo, más que una provocación estética, un escándalo entre otros ${ }^{37}$. "Colonización =civilización" era una equivalencia aceptada universalmente; si los surrealistas estaban en contra del primer término era porque también estaban en contra del segundo ${ }^{38}$.

El militante socialista Marcel Mauss había alabado los funcionarios de las colonias - "esos artesanos de las sociedades nuevas que son los colonizadores y los administradores coloniales (apud Fournier, 1994: $3573^{39}$ - ; más aún, había subrayado la necesidad de que la futura etnografía francesa fuese un instrumento al servicio del poder colonial, poder que no sólo no cuestionaba, sino que ensalzaba. Su idea era que los pueblos colonizados necesitaban a sus colonizadores: "su evolución y su progreso dependen casi exclusivamente de la administración que se les brinde" (apud Fournier, 1994: 503, n. 2; que habla del "colonialismo ilustrado" de Mauss). Leiris diría en 1945 casi lo mismo:

[En caso de abandono por las potencias europeas] los negros recaerían en una miseria mucho mayor de lo que pueden conocer en la actualidad. Sus jefes los explotańan más duro que nunca. Reinarían la enfermedad y la guerra sin fin. Lo que es necesario es mejorar sin cesar nuestra colonización [...], garantizaral indígenala mayor libertad posibley asociarlo [...] a obras colectivas. (apud Armel, 1997: 447)

Una década más tarde, cuando ya había escrito "L’Ethnographe devant le colonialisme", texto que "constituye el acta de nacimiento de una etnología crítica" (Fabre, 1999: 224), convirtiéndose así en uno de los censores más agudos de la etnografía colonial que él mismo había practicado, Leiris daba cursos a los futuros funcionarios de ultramar en el cuadro de Dirección de Tropas Coloniales (Armel, 1997: 471).

La Misión, por su parte, no sólo estaría al servicio del sistema colonial: era un hecho colonial; sus miembros - incluido Leiris - fueron emergente metafórico y metonímico del poder colonial en forma privilegiada y emblemática; eran representación suya al mismo tiempo que producto reproductor. La cuestión política y la epistemológica son 
Revista de Antropologia, São Paulo, USP, 2002, v. 45 noㅡ.

correlativas: una forma de trabajar se correspondía al lugar social que el sistema le daba ${ }^{40}$.

\section{La misión en movimiento}

La misión se condujo en un estilo conquistador, hasta depredador; los expedicionarios actuaban como si debiesen aprovechar esa oportunidad exclusiva, esa única y rápida estancia, y llenar sus alforjas de todo lo que encontrasen a su paso: objetos materiales para el Museo Etnográfico del Trocadero - lo prioritario - , fotografías y filmaciones, descripciones de rituales, genealogías, narraciones, vocabularios, animales vivos y muertos, etc. No pudieron hacerlo, sin embargo, con la misma intensidad en todo su trayecto. Hay dos etapas diferenciadas de la misión, la primera en territorio colonial francés y la segunda en la entonces casi única nación independiente africana, la que nunca había sido colonia de nadie, Etiopía ${ }^{41}$ (además de breves períodos en el Congo belga, el Sudan anglo-egipcio y la Eritrea ocupada por los italianos). La diferencia del trabajo en una y otra puede ser medida; mientras que en la primera se recogían 303 objetos al mes, en la segunda, sólo 17 (Caltagirone, 1988: 4).

La etapa etíope de la expedición resultó un duro anticlímax a la vida protegida bajo bandera francesa, además de las breves temporadas bajo la inglesa y la belga: mes y medio de espera en la frontera para el permiso oficial, enormes dificultades para después poder salir, prohibición de acceder a territorios conflictivos en los que G riaule suponía poder investigar, acoso de las autoridades locales, que llegaron a encarcelar a algunos de los informantes ${ }^{42}$. No faltaba razón a éstas; la conducta de la Misión fue de hecho delictiva, ya que exportaron obras de arte que obtuvieron por procedimientos dudosos escondidas en falsos fondos de sus baúles o sacadas del país con otros procedimientos clandestinos. Aún más; al verse acosados por las autoridades etíopes, los franceses destruyeron piezas, como cuenta Leiris (24-XI-32): "Roux [... ] me in- 
forma lo que está ocurriendo: destrucción de la plancha del altar que nos acusan de haber robado [... ], objeto cuyo descubrimiento nos podía llevar ni más ni menos que a una masacre".

El caso de mayor magnitud fue el de unas pinturas de comienzos del siglo XVIII que adornaban la Iglesia de San Antonio, cambiadas por unas reproducciones muy fieles hechas por $\mathrm{G}$ aston Roux el pintor que acababa de llegar, con D eborah Lifchitz a Gondar ${ }^{43}$ para sumarse a la expedición, además de otros temas religiosos realizados por Lutte, $\mathrm{G}$ riaule y, unos pocos, por Leiris. Esta empresa ocupó lo principal del esfuerzo de los componentes de la Misión - salvo Lifchitz y Leiris durante su estancia en Gondar.

Un segundo caso, en otra iglesia de la región, fue abortado por las autoridades etíopes, advertidas de lo ocurrido en Sto. Antonio. G riaule no aceptó de buen grado esta cortapisa a su voluntad; armó a sus hombres y los condujo en una incursión que intentó llevarse las piezas sin conseguirlo (Leiris, 5-IX-32). Un segundo intento terminó con un enfrentamiento cuerpo a cuerpo en el que Griaule llevó un puntapie en sus partes (: 2-XI-32).

Es verdad que la cuestión de haberse llevado las pinturas de Etiopía a Francia no es tan fácil de juzgar, de juzgar negativamente, quiero decir; por un lado había en el momento una suerte de lugar común proveniente de la larga tradición europea de rapiña por la que el código de Hammurabi, los frisos del Partenón o los tesoros de la tumba de Tutankamón se encuentren en museos europeos. Por otro lado, el hecho de que esas pinturas, que todavía están en las salas del $\mathrm{MH}$ y que se mantendrán allí 0 irán al futuro museo de Branly, pero que tienen su supervivencia asegurada, con mucha probabilidad no existirían si no fuese por este rapto - el término es de Griaule -; años después la iglesia fue visitada por J. Tubiana y no había rastros de las copias de Roux ${ }^{44}$ (existe la leyenda de que fueron robadas pocos años más tarde por los invasores italianos). A ninguno de los miembros del equipo se le ocurrió objetar lo que se estaba haciendo, y todos colaboraron en mayor o menor medida; el propio Leiris 
Revista de Antropologia, São Paulo, USP, 2002, v. 45 nํㅡ.

reaccionó en forma muy airada (hasta contra su tan querido Roussel) al leer las críticas aparecidas en la prensa francesa ${ }^{45}$. Hubo al respecto una versión oficial auto-exculpatoria de los expedicionarios (Roux, 1935): habían sido los propios sacerdotes coptos quienes insistieron en el trueque, seducidos por las ventajas del nuevo material traído por los franceses.

A hora bien, G riaule (1934) no consiguió dominar las ganas de que se supiese cuán astuto había sido al agenciarse estas pinturas únicas, cuánto se le debía por haberlas traído a tierras civilizadas, único lugar donde se les daría el valor que merecían y, en un breve artículo periodístico, contaba en un lenguaje muy recargado y con un tono auto apologético ("Hay que llevar el oficio en el cuerpo para saltar el muro del recinto de una ruina tal, y caminar arrastrando las piernas por hierbas espesas, y tropezar con piedras de tumbas invisibles y respirar a todo pulmón la humedad cargada de incienso") cómo llevó a cabo todo tipo de engaño y ocultamiento para que los responsable del templo supusieran que el francés donaba a la iglesia las nuevas pinturas y les hacía el favor de retirar y quitar del medio las viejas por devoción religiosa; para explicar su generosidad sin despertar sospechas ("la menor señal de interés por las pinturas y todo está perdido") llegó a decir que se llamaba Antonio, como el santo patrono de la iglesia. D escribía también con detalle los diversos episodios del transporte del botín y de cómo por fin éste llegó a territorio británico.

D eja estupefacto el desparpajo con que $\mathrm{G}$ riaule hacía espectáculo público de su arrogancia. Arrogancia ante los nativos, pero no sólo ante ellos. También ante el gobierno etíope, con el reconocimiento de la obtención y exportación fraudulenta de las pinturas, y también ante la diplomacia francesa, que quería un acercamiento con el Emperador etíope, Haile Selasie ${ }^{46}$. Y también ante sus subordinados, a los que no comunicó su proyecto de sustitución más que por partes y, por último, ante quienes en última instancia pagaban con sus impuestos la aventura que protagonizaba, los ciudadanos franceses que visitarían el Museo: 
"un pequeño público burgués, muy compuesto, que la mayoría de las veces pasaría al lado de la cosa sin verla".

El aspecto político de la cuestión venía a agravar el conflicto. En su estancia anterior, G riaule había sido el protegido de Haylou Tecla Haimanot ${ }^{47}$, un jefe feudal cabeza de una rebelión contra el emperador, cuyo proyecto pasaba por la derrota de los poderes feudales centrípeto y la construcción de un Estado etíope unitario; tras la derrota de aquel, la misión al llegar a G ondar sólo se encontró segura montando su campamento dentro de los límites de la legación de la Italia fascista, país que poco después de la partida de los franceses iniciaría una guerra colonial genocida contra Etiopía y la ocuparía hasta 1941. Toda la etapa etíope del viaje, por otra parte, se cumplió en medio de un conflicto armado de gran envergadura, del que Leiris daba una y otra vez cuenta en su diario: 500 muertos un día, 200 el otro, unas decenas el siguiente, etc.

\section{$* * *$}

En fin, cualesquiera que hayan sido los avatares de la Misión, la insolencia colonial de sus miembros fue siempre la misma. La idea de aventura, de botín, de captura ${ }^{48}$, marcan el espíritu con que se llevó a cabo la misión. Y junto a ello, en sus maneras à la Tintín, el aire de jeunesse dorée ${ }^{49}$ del grupo de expedicionarios, de los que salieron en primer lugar y de los que se juntaron a ellos en diversas etapas del viaje: un grupo de jóvenes (el propio jefe de misión, G riaule, tenía 33 años) con poca o ninguna relación previa con la etnografía y que sólo de manera minoritaria irían a dedicarse a ella (de once, cuatro). La imagen ofrecida oscilaba entre el amateurismo - la faz aventurera de la Misión-, y la seriedad del especialista, su faz científica.

Griaule, tras haber pasado por la aviación, se había hecho lingüista; su experiencia de campo en Etiopía había sido como recopilador de textos amáricos. Esta es la presentación que de sí mismo hacía en el proyecto de la Misión: "Asistente del Laboratorio de Etnología. 
Revista de Antropologia, São Paulo, USP, 2002, v. 45 nํㅡ.

Encargado de Misión en Abisinia. Estudios de matemáticas especiales. Licenciado en Letras. Dipl. de la Escuela de Lenguas O rientales Vivas. Dipl. de la Escuela de Altos Estudios. Miembro del Instituto francés de antropología y de diversas "societés savants".

Leiris no tenía ninguna formación profesional previa, más allá de algunas conferencias de Mauss a las que había asistido de manera no sistemática, y unas pocas, muy pocas, lecturas antropológicas; su vida académica era también mínima, ya que obtuvo su licenciatura en Letras algunos años después de su regreso de la misión. Algunos de los participantes de las diversas expediciones eran simples auxiliares personales de $\mathrm{G}$ riaule (Lutten y Larget).

En misiones posteriores, G riaule mantuvo, aunque menguado, ese componente diletante. El ejemplo más vistoso quizás sea el de Hélène Gordon, una periodista que años más tarde fundaría la revista E lle y que seguramente daba la nota in por la que $\mathrm{G}$ riaule parecía tan cautivado; tras participar en la Misión Sahara-Sudán del 35, publicó en el Paris-Soir una serie de artículos con el discreto título de "En el antro de los demonios bebedores de sangre". Leiris, dicho sea entre paréntesis, tuvo un romance loco con esta mujer, una de las amantes del ardoroso $\mathrm{G}$ riaule.

Tintín, sí, pero también Tartarín, el personaje de Daudet padre que en su aventura argelina se perdía en una plantación de alcachofas, creyendo estar en el desierto, y que, pensando enfrentarse a un león, mataba un burro por el que fue obligado a pagar una pequeña fortu$n a^{50}$. Hay, al menos en el registro de Leiris, una cierta desilusión en ese territorio cuyo exotismo no termina de dejarse ver entre oficinas de correos y estaciones de trenes tan franceses como los de la metrópolis. La empresa no era todo lo excitante que hubiera podido esperarse. El territorio no tenía ya, ni mucho menos, el misterio que poco más de un siglo antes había engullido a Mungo Park sin dejar huellas (Hugon, 1998: 46). La carretera a Bamako, la capital de Mali, había sido construida más de cincuenta años antes y por ella pasaban no sólo los muchachos que iban a los grandes centros para trabajar, estudiar o incor- 
porarse al ejército francés ${ }^{51}$, sino también europeos de todo cuño, algunos de los cuales turistas, entre los cuales Leiris una y otra vez se siente incluido ("El viaje que hacemos hasta el presente no ha sido otra cosa que un viaje de turistas y no parece que vaya a cambiar" - 31-III32). Sólo al llegar a la frontera entre Sudán y Etiopía, parece Leiris alcanzar su sueño de otredad: "Cuántos kilómetros ha sido necesario que hiciéramos para sentirnos por fin en el umbral del exotismo", anota en su diario; y el día anterior:

Por fin ÁFRICA, la tierra de los $50^{\circ}$ a la sombra, de las convoyes de esclavos, de los festines de caníbales, de los cráneos vacíos, de todas las cosas comidas, corroídas, perdidas. La alta silueta del maldito famélico que siempre me ha obsesionado [iRimbaud?] se alza entre el sol y yo. Es bajo su sombra que camino, sombra más dura pero también más tonificante que el rayo más diamantino. (18-IV-32)

Exotismo, por cierto, que podía llegar a ser muy engañoso $0^{52}$. La mezquita de Y enné fue obra extravagante de un administrador colonial, tras haber destruido la vieja ("vandalismo metódico que inauguró Violletle-D uc"), esa sí - o vaya uno a saber - "original"53. "Los indígenas están tan disgustados con el nuevo edificio" - anota Leiris (21-IX-31) - "que es necesario castigarlos con prisión para que consientan en barrerlo" 54 .

\section{Notas}

1 Este texto, parte de un trabajo mucho mayor del que han sido publicados otros fragmentos (Giobellina Brumana, 2000, 2001, 2002), ha sido llevado a cabo en el marco de una investigación financiada por el Ministerio de Educación y Cultura español (BSO 2000-037); además, ha contado una ayuda de Movilidad también del MEC para trabajar en distintos archivosy bibliotecas de Paris. Agradezco ala Bibliotecadel Museo del Hombre, y a su directora, la señora Catherine D elmas, el acceso al material documental contenido en sus archivos. Las cartas, los artículos de prensa, las conferencias radiofónicas, etc. aquí citados sin indicación bibliográfica tienen esa procedencia. No he querido hacer más pesado el texto haciendo constar a cada momento la referencia del catálogo, a disposición en labiblioteca. 
2 Petit(1998: Cap. 1) presentaun actualizado resumen delainformación y discusiones sobre épocas, etapas y lugares de esta migración, en buena medida basado en introducciones y primeros capítulos de G riaule (1983 [1938]), Paulme (1940), Leiris (1948), Calame-G riaule (1987 [1965]), D ieterlen (1982). Para la autora, interesada en la vigorosa migración actual de este grupo, la cuestión establece un pasado real y mitológico de las corrientes demográficas del presente. La migración originaria, por otra parte, no está ausente de la vida religiosa actual de los dogon ya que los altares (lebe) deben incluir en su construcción arcilla traída del país originario, en cuyo suelo fue enterrado Lébe, el primer antepasado mortal.

3 Sobre el comercio de estos objetos, vale la pena leer el testimonio incidental de un etno-psiquiatra italiano que ha trabajado mucho tiempo en país dogon, al hablar de un hombre con quien se encontró en casa de un informante suyo: "Un anticuario, 0, con mayor exactitud, un hombre de acción enviado por anticuarios americanos. Adquiere los objetos de arte de los que han decidido deshacerse los guardianes de fetiches que abrazan una de las nuevas religiones. Y con jóvenes de la ciudad [Bandiagara] organiza robos de estatuas que llegar a valer varios millones en el mercado del arte. D eben, sin embargo, ser muy prudentes; hace poco, un cazador del acantilado robó el fetiche de un poblado de la llanura. Tres días más tarde, la estatua llegaba a los Estados Unidos, pero los habitantes del poblado habían encontrado al ladrón; le rompieron las piernas y lo abandonaron en un camino" (Coppo, 1998: 104).

4 D atos de 1995. Los otros grupos principales, según la misma fuente: árabes: 106.000; bambara: 2.700.000; bomu: 305.000; boso: 217.000; kassonké: 120.000; malinké: 650.000; peuhl: 1.086.000; songai: 600.000; soninké: 700.000; tuareg: 430.000. Esta información, es necesario aclararlo, habla de grupos lingüísticos, no degrupos étnicos.

5 Hay, por cierto, trabajos recientes sobre los dogon, como el de Petit que he citado en la nota 1, un número monográfico de Clio en A friquededicado a cuestiones de organización política (Jolly, 1999; Martinelli, 1999; Bouju, 1999); Holder(1998), sobre la institución de la esclavitud; Jolly (1994) sobre la implantación de otros cultos; Liberski (1989) sobre cuestiones de contaminación. Huet (1994) ha escrito una monografía que focaliza la relación entre hábitat y sociedad dogon. 
6 Mito presente aun en aquellos que en la actualidad tienen un intenso vínculo con los dogon. Coppo (1998: 121), a quien he citado ya, dice, hablando de la Misión: "En ese tiempo, nadie en Europa, ni siquiera los africanistas, conocía a ese pueblo".

7 G eorges Henri Rivière, subdirector del Museo de E tnografía del Trocadero, el futuro Museo del Hombre, a cargo de sus cuestiones más prácticas y, por lo tanto, de la colaboración de éste con la Exposición, escribe a Griaule, ya en territorio dogon: "Este fin de exposición es lúgubre. La lluvia empapa las murallas, el frio hace languidecer las palmeras y temblar a los indígenas (a pesar delos miles de radiadores eléctricos)" . En la misma carta (31-X-31), una referencia a danzas de un grupo africano no identificado: "El Dr. Chauvet ha dado, bajo los auspicios del Instituto Labouret, una increible sesión de danzas y música africanas que ha sido un ridículo y un formidable fiasco: ha transtornado a los desdichados indígenas, les ha interrumpido, les ha 'animado'; ha hecho el ridículo fuera de toda medida. Un comunicado a la prensa, redactado por él, hablaba sin parar del autor, él mismo Chauvet; es para morirse. El público cada vez más inquieto, se fue antes de que acabase".

8 D esde su primera llegada a tierra dogon se hizo uso del cine etnográ fico. Hay una película de un ritual fúnebre, realizada por E ric Lutten y conservada en el Comité del cine etnográfico del Museo del Hombre (títulos y metrajes de los fragmentos: A salto a las terrazas - $50 \mathrm{~m}$-, Lamentación de las mujeres - $20 \mathrm{~m}$-, Combates en la plaza pública - $100 \mathrm{~m}$-, Tiro de aro y fusil - $50 \mathrm{~m}$-, Rito del baga bundo - $30 \mathrm{~m}$-, L os cazadores en la plaza pública - $20 \mathrm{~m}$-). Griaule está ligado por hazañas como ésta al nacimiento de lo que se ha dado en llamar antropología visual. El personaje clave en esto es Jean Rouch ("hijo de G riaule", lo llama Paul Stoller [1992: 15]) que acompañaría años más tarde a G riaule en sus visitas a país dogon (cf. Loizos, 1997; debo a Francisco Ferrándiz ambas referencias). Buñuel fue el candidato a cineasta de la expedición del 1931-1933 (Massonet, 1997: 109), pero prefirió abocarse a la película que iría a filmar en las Hurdes con dineros proporcionados por un billete de lotería premiado.

9 Sintonía que puede sintetizarse en la fórmula de que "el pensamiento africano es un pensamiento culto" (Bastide, 1978 [1958]: 11), conclusión a la que este autor llegaba de manera independiente al "hallazgo" de G riaule: "Cuando, en 1944, fuimos por primera vez a Bahía, nada sabíamos de los trabajos de Marcel 
G riaule. Fue sólo después de la guerra que tomamos conocimiento de ellos. Constituyeron para nosotros un aliento precioso, pues confirmaban nuestra convicción primera" (ídem).

Veamos lo que al respecto dice una estudiosa de Bastide, Fernanda Peixoto: "Las formulaciones de G riaule llegan a Bastide mediante D ieu d'eau (1948) que obtiene gran aceptación en el medio académico y extra-académico francés por los años 50. La serie de entrevistas hechas por el africanista francés con O gotemmêli, cazador D ogon, permite al intérprete intrincarse por los enredos de una cosmología africana de extrema complejidad, recorrer un sistema depensamiento hábil en la realización de operaciones lógicas, en el establecimiento de correspondencias cosmobiológicas, como los verificados entre los hombres y la naturaleza, y en las relaciones de los hombres entre sí. Los análisis de G riaule son seguidos de cerca por Bastide, sobre todo cuando se vuelca al análisis de la filosofía sutil del Candomblé" (2000: 109; énfasis te Peixoto).

10 Éxito este último que ha tenido reverberaciones hasta hace no mucho tiempo. Recordemos que el coronel Kurtz, el personaje representado por Marlon Brando en A pocalypse now, tenía como manual de su locura a The $\mathrm{G}$ olden Bough. 0 tra vuelta de tuerca haría pensar en el texto en que se basaba la película, In the heart of darkness (y en su autor, Conrad, esa contrapartida de Malinowski), en el remonte del río Congo del que trata ese relato, presente a la memoria de Leiris remontando el valle del Níger.

11 En la financiación de la Misión D acar-Y ibutí, Rivière tuvo también un papel central; en los archivos del Musée de l'Homme se guardan decenas de cartas suyas a organismos de todo tipo en busca de fondos (G riaule le escribe: "acabarás secando todo París") y otras de agradecimiento.

12 Según Jamin respecto a esta publicación, que tuvo sólo dos años de vida, se han publicado "al menos una cincuentena de artículos, memorias, tesis, capítulos de libros o libros enteros"(1999: 262, n. 15) .

13 Uno delos textos de Leiris "L'oeil de l'ethnographe", vuelto a publicar en Z ébrage, da cuenta de su visión de Africa antes de emprender viaje con $\mathrm{G}$ riaule. Visión colonial, visión infantil, visión de niño colonial, como el propio Leiris insiste en mostrar. Ver al respecto el interesante análisis de Cogez (1999a y 1999b). 
14 Rivet es un personaje esencial en los primeros pasos de la antropología francesa: fundador en 1925 junto a Mauss y Lévy-Bruhl del Instituto de E tnología de la Universidad deParís, fue nombrado cuatro años más tarde director del Museo de Etnografía que, en 1937, se convertiría en el Museo del Hombre, siempre bajo su dirección. Médico militar en sus comienzos, llegó con una expedición destinada a la medición de un meridiano al Ecuador, donde nació su interés por la Arqueología y la Etnografía. Militante del PSF - como Mauss - debió exiliarse durante la ocupación alemana. Para una bio-bibliografía suya ver Laurière (1999).

15 Caso policíaco, por otro lado, en el que Genet se basó para escribir L es bonnes y que fue una especie de estandarte subversivo para surrealistas como Éluard y Peret. En la revista belga D ocuments 34 (Intervention surréaliste) - nada que ver con la D ocuments de Bataille - de junio de 1934 he encontrado un dibujo firmado P.N. (¿Paul Nougé?) "Hommage aux soeurs Papin”.

En este artículo, Lacan se acercaba a su primera gran heterodoxia respecto al freudismo, la idea de que las psicosis eran abordables por la cura analítica. Roudinesco (1995: 103ss) muestra la importancia del caso Papin, así como de los dos artículos publicados en Minotaure, en las futuras elaboraciones del psicoanalista.

El presentador anónimo de la edición Fayard de D ieu d'eau ve esta conjunción con una exaltación muy francesa: "G riaule y Leiris entregan [en M inotaure] las primeras huellas de su proyecto africano, Lacan consagra allí a las hemanas Papin algunos de sus primeros textos publicados, a la escritura de las mujeres locas. Los tres en el 'continente negro'. La realidad de un lado, la metáfora del otro. Unos en Africay los otros en la feminidad. A veces hay coincidencias curiosas".

16 En un texto posterior, Leach insistía: "Aunque puede ser necesario un conocimiento de la filosofía existencialista para comprender la postura de LéviStrauss..." (1975 [1969]: 177). Fabre (1999: 229) aborda la relación Sartre/ LéviStrauss desde fines de los 40 hasta comienzos de los 60 y encuentra, para ese período y con base más concreta que Leach, una cierta cercanía entre el segundo y los planteamientos existenciales del primero. Esa relación, rota con el último capítulo de L a pensée sauvage, dejó un retoño, Jean Pouillon, que siempre intentó una unificación coherente del pensamiento de sus padres intelectuales (Pouillon, 1975 [1965]).

17 Cf. G iobellina Brumana (1999: 99). Manuel D elgado (1999) ha dado a un capítulo de un libro suyo el título de "La Sociedad y la Nada". Su razonamiento, 
que en un par de ocasiones se apoya en citas de textos míos, emplea la categoría sartreana de "nihilización", como forma de entender que los márgenes son un centro neurálgico de la realidad social. Afirma en la página 108: "esa nihilización de lo social sirve para que una comunidad se coloque ante las conclusiones inherentes a su propia condición orgánica, como si se quisiese recordar que, en tanto que ser vivo, es polvo y en polvo habrá de convertirse" (énfasis de D elgado).

18 El estúpido tono burlón de G eertz (1989: cap. 3) al abordar el escrito de Evans-Pritchard sobre su experiencia bélica es, a mi entender, la muestra más irritante de la torpe gamberrada escolar en que se puede convertir la posmodernidad antropológica.

19 "Tengo la impresión de que en la antropología anglosajona, en particular la inglesa, a pesar de que las relaciones con el mundo de las artes y de las letras han estado menos afirmadas que en Francia, las monografías son menos rígidas y por lo tanto menos aburridas. Me vienen a la cabeza sobre todo las obras de Evans-Pritchard y de Malinowski, donde la expresión científica más aguda no excluye una dimensión poéticay, a veces, épica” (Pricey Jamin, 1988: 41).

20 Paulme en entrevista con Annie Dupuis daba esta imagen sobre la diferencia entre la urgencia parisina y el verdadero ritmo de los dogon: "Lo que nos habían dicho en París era que había que darse prisa porque todo iba a desaparecer. De hecho, las cosas continúan exactamente igual que antes. Sigue sin haber carretera; el coche te lleva a lo alto del acantilado y después nada de nada. [Según un investigador holandés que hacía trabajo de campo en ese momento, 1987] ...las cosas han quedado tal como yo las conocí... D ebido a que el país es muy pobre, que no se puede hacer crecer gran cosa porque tampoco hay agua, cultivan su mijo y es todo ... [...]. Los muchachos salen para ganar su dote, conocer un poco la vida, y después, cuando regresan, cuando las pilas de los transistores se han gastado...vuelven a coger la azada y van a trabajar exactamente como sus padres... Por lo tanto, se puede pensar que habrá islas como ésta que subsistirán porque no son interesantes para la vida moderna... Claro, las máscaras se pintan con esmalte industrial, pero su función subsiste, eso es lo importante" (Lifchitz y Paulme, 1987: 57, n.32). 
21 No sé a qué se refiere; quizás se trate de la "masacre de D ongoi”, escaramuza en la que tuaregs rebelados contra el poder colonial francés destrozaron una columna formada, en su inmensa mayoría, de soldados senegaleses (Raillé, 1894).

22 El presupuesto anual del Museo del Trocadero, que con el tiempo se convertiría en el Museo del Hombre, era de 25.000 francos de la época (Mauss, 1969 [1913]: 422), un equivalente a 63.000 euros. Casi dos décadas más tarde, en 1930, la recaudación anual por las entradas al museo apenas superaba los 21.000 francos (poco más de 9.000 euros). Los redactores del Bulletin du Musée d'ethnographie de Trocadero, n.1 (enero de 1931), de donde tomo este dato, no perdían las esperanzas: "E stamos convencidos de que las entradas pagas se convertirán, cuando el museo esté reorganizado, iluminado y calefaccionado, en una fuente importante de ingresos. En la actualidad, la afluencia es considerable los domingos (varios miles de personas [que, por ser día festivo, no pagaban entrada])". En el número siguiente del Bulletin..., encontramos una declaración de casi ruina: "D ebido a la falta de presupuesto, un auxiliar técnico, la señorita La Torre, ha debido ser despedida -lo que ha comprometido gravemente el funcionamiento del servicio, tan útil, de referencias fotográficas. En la actualidad ya no hay presupuesto suficiente para retribuir a los dos bibliotecarios y al guarda nocturno; tendremos que encarar la interrupción de esos servicios esenciales si no se ponen urgentemente recursos a disposición de la Sociedad [de Amigos del Museo Etnográfico]".

23 Lévi-Strauss (1955: 15) describe con gracia la triste y vetusta marginalidad con que la producción etnológica encontraba eco en el París a mediados de los años 20. Recuerda: "el pequeño anfiteatro sombrío, gélido y estropeado [donde] el proyector enviaba sobre una pantalla demasiado grande, con lámparas demasiado débiles, sombras imprecisas de las que el conferenciante, la nariz pegada al panel, apenas conseguía percibir manchas de humedad que ensuciaban las paredes. [...] Un cuarto de hora después del tiempo anunciado, uno se preguntaba con angustia si habría público, además de los pocos habitués cuyas siluetas estaban dispersas por las gradas. Cuando se desesperaba, la sala se llenaba a medias de niños acompañados de madres o de sirvientas, unos ávidos de un cambio gratuito, otros cansados del polvo y del ruido de afuera".

24 "El público no se interesaba más que en la anécdotay en el aspecto novelesco", decía Mauss en 1913 (: 405). Q uizás, dicho sea de paso, haya sido el éxito editorial de Frobenius lo que provocase el recelo con que se refería a la obra del autor 
del D ecamerón N egro (Frobenius, 1938): "Frobenius [...] ha comenzado la publicación de toda una literatura que dice haber descubierto en el círculo [círculo = división territorial administrativa] de Segou [o sea, por donde trabajaría años más tarde $\mathrm{G}$ riaule \& Co.]. Hasta aquí se ha limitado a la edición de textos eróticos. Aunque nos permitamos dudar del valor de los documentos del Sr. Frobenius, ni por un instante dudamos de la existencia, entre los pueblos de la familia mandinga de una literatura considerable" (: 407, n. 12).

25 El Museo del Hombre, por otra parte, iba a concentrar toda la investigación etnológica hasta entonces dispersa. Cuando se anunció que se iba a derruir el MET y en su lugar se levantaría el MH, Rivière (1935) observaba: "Pensad que hoy el Instituto de Etnología está en la calle St. Jacques, la galería de antropología en el Jardín Botánico, el laboratorio de antropología en la calle de Buffon y nosotros en la otra punta de París".

26 Cinco años más tarde, recordaba Rivière (1935): "Mucho nos costó montar 250 vitrinas, expulsar el desorden, la obscuridad, la mugre de 30 años de abandono. ¿Q ué trabajo para atraer al público! Necesitamos 3 años para persuadirlo de que unajuventud ardiente reunida bajo la amable férula del Profesor Rivet- clasificaba, catalogaba, exponía".

27 El que la información no fuese elaborada por los propios redactores, sino simplemente refrita del material enviado por el Museo hace queallí donde los otros periódicos, transmitiendo el primer comunicado de la Misión, digan que esta "proyecta dedicarse los próximos meses al estudio de las poblaciones sudanesas", en el Paris-M idi (17-IX-31) se la destineal "estudio delas publicaciones sudanesas".

28 "Cuando vivamos en medio de sus hermanos de color, trataremos de captar lo mejor posible a estos pueblos africanos, por lo general tan poco conocidos, para hacerlos amar más. [... ] Al Brown sabrá poner sus puños al servicio de esta causa de interés universal: hacer posible entre los pueblos coloniales y los pueblos colonizados, gracias a un mejor conocimiento de la mentalidad de estos últimos, una colaboración más fecunda, que se ejerza en un plan menos brutal al mismo tiempo que más racional” (Griaule, en el programa de la gala de box).

29 El relator ante la Asamblea de la Comisión de Finanzas que proponía la subvención, M. H. Ducos, basaba la necesidad de este apoyo oficial en 
razonamientos que pronto veremos en boca de los propios antropólogos: el conocimiento de la realidad de los sujetos coloniales era útil para racionalizar la dominación. Uno de sus argumentos, sabiendo lo que hoy sabemos sobre las prácticas de Leopoldo II y su hijo, el colaboracionista Leopoldo III, hiela la sangre: "La propia Bélgica nos da un brillante ejemplo: su Congo, desde el punto de vista que aquí encaramos, puede ser considerado como un modelo de colonia estudiada y explotada racionalmente, donde sabios, funcionarios y colonos trabajan de común acuerdo para el mayor bienestar de los indígenas y de la prosperidad nacional" (C ahiers E thnologiques, 1984: 73).

30 Una de las investigaciones programadas - no sé si sellevó a cabo, ni para qué servía tal información - era sobre "manchas mongólicas", tema impusto, al parecer, por el somatista Rivet. Esta cuestión tambien atrajo la atención de los scouts que habían ido al Canadá y de la Misión de Charcot a Groenlandia (1934). En la ficha que se llevaba a África se pedían los siguientes detalles: lugar, población, nombre, sexo, edad, lugar de nacimiento del niño, del padre, de la madre. Carácter de la mancha: lugar, color, forma, dimensión, número.

31 ¿Mucho o poco? ¿Cómo medirlo? En la misma sesión, la Cámara concedía 2.500.000 francos (1.360.000 euros) de crédito suplementario para cubrir los gastos de una expedición de delimitación de fronteras entre la G uyana francesa y Brasil, además de una misión científica adjunta.

32 Entre los cuales laFord, que suministró un par de camiones y un coche, tal como la empresa lo publicitaba en anuncio a toda página en el número monográfico de M inotaure dedicado a la Misión: "Han hecho los 20.000 km de esta expedición sin ningún fallo". D enise Paulme (G rossi, 1999: 108) dice que la expedición del 35 en la que ella participó también contó con un apoyo similar, esta vez de la Renault. Es curioso que el nacimiento de la etnografía francesa haya sido patrocinado por una empresa estadounidense; quizás la Ford estuviese más en consonancia con la modernidad a la que Griaule aspiraba. Este hecho, sin embargo, no dejó de irritar a un coronel que, en una nota de Franœ Militaire, reprochó la falta de solidaridad con la industria militar: “¿Q ué dirán los indígenas del África O ccidental Francesa cuando vean llegar a nuestros camaradas abordo de coches americanos?" (5-V-31). G riaule no era hombre de dejar pasar críticas y respondió inmediatamente: 1) los vehículos Ford se fabricaban en Francia, con mano de obra francesa; 2) las otras compañías francesa hacían rebajas 
irrisorias; 3) no es cuestión de un pobre cuentífico laborar a favor de la industria nacional - que para colmo lo había menospreciado -; 4) la Rockefeller Foundation, Al Brown y su manager - americanos ellos - habían colaborado con toda generosidad en el financiamiento de la Misión.

33 En el prólogo a una de las obras producidas con el material recolectado entre 1931 y 1937, G riaule (1983 [1938]: V-VIII) agradecía a instituciones y personalidades que apoyaron su proyecto. Encontramos en el largo listado nueve altas instancias estatales (Ministerios, Gobiernos y Comisariados coloniales - la Somalia francesa y el Á frica Ecuatorial - ), diez instituciones académicas (academias, universidades, museos), siete bancos y empresas, once sociétés savantes y fundaciones, entre las que destaca la Rockefeller Foundation. Ésta ya había financiado en el período 1928-1929 la primera incursión de G riaule a Etiopía para una investigación de campo sobre la lengua amárica. Pocos años más tarde, sostendría la Misión Sahara-Sudán, también dirigida por Griaule, y la prolongada estancia de D enise Paulme y D eborah Lipchitz entre los dogon en 1935. Sobre la importancia de la presencia de esta fundación para el desarrollo de las ciencias sociales en Francia, ver Mazon (1985); sobre el papel fundamental de Mauss al respecto, Fournier (1994: 459).

En la lista de "personalidades" individuales destacan dos princesas y una marquesa, un mariscal, además de artistas del prestigio de Paul Valéry, Georges Huisman y Raymon Roussel (aquel que había viajado por África sin salir de su casay que tanta influencia tendría sobre Leiris [Cogez, 1999b]). En fin, letout Paris!

34 Un arte universal, sostiene uno de los personajes de Cortázar en Rayuela. Schaeffner, el musicólogo dela Misión y futuro marido de D enise Paulme, tuvo la chocante experiencia de que el criado negro quele servía no sintiese atracción alguna por los discos de jazz que le hacía escuchar mientras que adoraba el Bolero de Ravel (Jamin \& Williams, 2001: 12).

35 Leiris sobre la relación entre jazz y África: "a escala deÁfrica, eljazz es una pequeña travesura artística encantadora, mientras que África, a la escala brillante del jazz, es un revoltijo de cosas sombrías, anodinas, a veces de oropel pero casi siempre miserables" (carta a Zette del 23-II-32). Y también: "Primera manifestación de los negros, mito de edenes de color, que debía llevarme hasta Á frica y, además de África, hasta la etnografía" (Leiris, 1999 [1939]: 160). 
36 En 1996, el Centro Pompidou presentó una hermosa exposición en la que se pasaba, sin solución de continuidad, de máscaras africanas a máscaras picassianas; costaba trabajo distinguir la frontera entre unas y otras. Pero es necesario, al menos según Leiris, llevar esta influencia a su real medida: Sé que hay muchos intelectuales africanos o antillanos que imaginan que sin el arte africano jamás hubiese habido cubismo. Es completamente falso. El cubismo se derivó esencialmente de Cézanne. Por otra parte, Picasso habría podido hacer lo que hizo sin 'arte negro' y, si se insiste en ese tipo de aproximaciones, habría también que hablar del arte ibérico que lo influenció bastante" (Price \& Jamin, 1988: 38).

Ahora bien, por más que la moda artística haya sido aprovechada por la Misión, la etnografía y la museografía que de allí salieron estuvieron, por así decir, a contracorriente de esa onda. Leiris se refiere, en la misma entrevista, al "antiesteticismo de Rivièrey de su entomo de esa época. Ya no se quería oír hablar de 'arte negro', se había vuelto demasiado de moda”.

37 Provocación que mostraba su mayor eficacia cuando sus efectos eran violentos. Breton cuenta cómo en la época de la fundación del surrealismo, la provocación antifrancesa se convertía en un hecho de calle: "Leiris estuvo a punto de ser linchado por haber proferido desde la ventana, luego en la avenida, gritos expresamente sediciosos" (1969 [1952]: 115). Se trataba, según refiere Leiris (Price \& Jamin, 1988: 30), de "mueras" a Francia y de "vivas" aAbd El-Krim, el jefe dela resistencia marroquí primero contra tropas españolas y luego también francesas.

38 En los estremecedores días que siguieron al 11 de septiembre, Jean Clair, director del Museo Picasso de París, escribió en L e M ondeun artículo en el que planteaba que el atentado de Nueva York de alguna manera había sido un deseo de los surrealistas. Entre otras cosas, afirmaba: "En nombre de un 'misticismo' confuso y un 'furor' desenfrenado - para usar términos que aparecen en sus escritos, es a un ataque en toda regla contra la lógica, contra la razón, contra las Luces, a lo que se entregan, a mediados de los años 20, últimos herederos del romanticismo negro, los jóvenes surrealistas. Lo que quieren es la destrucción de todo lo que ha dado a 0 ccidente su supremacía".

39 En otra ocasión, Mauss había afirmado: "En forma alguna nos faltan observadores. No hay personal colonial más apto para comprender al indígena, más íntimo con él que nuestros administradores, nuestros oficiales, nuestros médicos. En parte alguna hay un cuerpo más capaz de inspirar confianza al indígena 
y de suscitar en él el entusiasmo necesario para que supere su timidez o su humor. No hay sabios que estén a tal punto desprovistos de prejuicios, tan peligrosos en esos estudios de raza y de religión" (1969 [1913]: 431).

40 Supongo que el indirect rule con que los británicos organizaban la imposición de su autoridad entre los pueblos colonizados daba un margen de maniobra mayor a sus antropólogos en relación a la autoridad colonial que la política francesa de gobierno directo de los nativos. Es curioso descubrir que personal muy ligado a la política colonial inglesa pensase que la francesa era superior (Lord Hailey, 1945: 236ss.) por la integración que pretendía. El antropólogo inglés tenía la administración de sus compatriotas a distancia; el francés, vivía muchas veces en casas de la propia administración local, como cuentan Condominas o Paulme.

41 La única nación con tradición escrita en una lengua africana, el ghezo, que todavía en la actualidad sirve de lengua litúrgica al clero copto. A unque la leyenda que hace remontar el reino etíope a Salomón y la reina de Saba bíblicos sea muy dudosa, sí hay noticia documental de la primera dinastía cristiana en el 333. Etiopía iba a pasar al primer plano mundial poco después de la estancia de la Misión a raíz de la invasión fascista. Un cuarto de siglo antes, otros "niños terribles", esta vez ingleses, un puñado de componentes del grupo de Bloomsbury - entre los cuales la propia Virginia Woolf con cara tiznada y barba postiza - engañaron al Almirantazgo británico haciéndose pasar por el emperador abisinio y su corte, en una visita al buque insignia de la flota con todos los honores militares (Stephen, 1999 [1936]); pocas cosas habían entonces más inverosímilmente exóticas que Abisinia. Exóticas y novelescas; Hugo Pratt, el creador de Corto Maltés, Emest Pike y el Sargento Kirk, ha dedicado varios álbumes a este país en el período de la segunda guerra mundial, que fueron más tarde reunidos bajo el nombre de E tiópicas.

42 Los propios domésticos senegaleses cambiaron su actitud sumisa; recordaban viejas afrentas de los expedicionarios y les hacían notar que "ya no estamos aquí 'en la tierra de los europeos, sino en la de los hombres negros'”" (Leiris, 1996 [1934]: 7-VI-32).

43 Información sobre G ondar que debemos a Gaston-Luis Roux: fundada en 1630, había sido capital del país. Población, 6000 habitantes, la mitad de los cuales eclesiásticos de diverso nivel, pertenecientes a la iglesia copta etíope, para la que 
era tan hereje un católico, un protestante, un judío o un musumán; 44 templos. Colonias griega y portuguesa, bajo cuyas órdenes se habían construido numerosos castillos dos o tres siglos antes. Estos datos forman parte de "La peinture en Abyssinie", artículo aparecido en la revista A rt et C ouleur, 43 (10-14), oct. de 1933, aunque los he tomado del original mecanografiado.

44 W. Staude (1959) visitó la iglesia en 1956; según su testimonio quedaban todavía un S. Jorge matando al dragón y una cabeza de los •veinticuatro curas del cielo.

45 Henri de Monfreid, redactor del Petit Parisien, que años después iba a realizar una exposición fotográfica en el Museo del Hombre (Rivages de la M er rouge), en carta del 6-II-33, fechada en Etiopía, a Rivière dice: "El hecho de haber querido llevarse por la fuerza, en una iglesia abisinia una pintura antigua desgarrándola es desgraciadamente exacto. Las violencias de las que [G riaule] se queja no son más que las consecuencias de su acto, que las personas civilizadas consideran un poco como el de un vándalo".

46 Haile Selaisie, el Ras Tafari, de cuya mitologización jamaicana proviene el movimiento rasta, conocido mayormente por la divulgación que Bob Marley le dio en los años 70.

47 Este hombre se convertiría tras la anexión italiana en una suerte de Quisling etíope. Fue el último jefe pro-italiano en rendirse, no ante la $G$ ideon Force capitaneada por el negus, sino ante las fuerzas británicas (D el Boca, 1985: 46). G riaule, y después Roux, quedaron seducidos por este hombre que los recibió - a aquél en G odjam durante su primer viaje a E tiopía, al segundo en Addis Abbaba, ya bajo control imperial - con toda magnificencia. Este último, en conferencia radiofónica (Roux, 1935), nos dejó este retrato: "Un hombre muy guapo que cargaba con alegnía sus sesenta años. En su actitud, en sus gestos, en su lenguaje había una real majestad. En su cara muy bronceada, de nariz aquilina, un mentón acometedor adornado con un bigote negro corto y un fina banda de barba, se leía la astucia del campesino y el corage del guerrero del tiempo de Menelk".

48 El término "botín" aparece en la introducción de Rivet y Rivière (1933: 5) al monográfico de Minotaure. Sobre "captura", tenemos el D ecreto del Ministerio de las Colonias, cuya reproducción en $\mathrm{L}$ es $\mathrm{A}$ nnales C oloniales del 12-V-31 ilus- 
trala página 17 de Jamin, 1996a: "Artículo único: Seacuerdael permiso de captura científica, válida para todala duración de su viaje por el conjunto de las Colonias del África O ccidental Francesa, al Sr. Marcel G riaule, encargado de misión".

49 Rivière, en las negociaciones que no tuvieron éxito con la productora cinematográfica Paramount a las que antes me he referido, describía así a los futuros expedicionarios: "it is also worthy of note that the staff of the expedition as weell as being experienced, is young, gay, and with an excellent 'moral'" (carta del 23-IX-1930).

50 Esta referencia no es fruto del capricho. Tartarín, como fantasma grotesco de una aventura en tierra exótica, como anti-héroe colonial, está presente en L 'A frique fantôme cuando (4-XI-31) Leiris califica de "tartarinada" la muerte de un caimán a manos uno de sus compañeros. También Mauss, pensando en la ridícula vestimenta que $D$ audet daba al personaje, escribía antes de hacer su viaje a Marruecos a un amigo: "¿Podría darme algunos detalles sobre la manera en que debería equiparme. No quiero tartarinar, pero tampoco quiero pasearme por las montañas del país en zapatitos" (apud Fournier, 1994: 582; énfasis de Giobellina Brumana). Condominas (1991: 177), a propósito del arma que llevaba en su mochila: "Jamás he tenido el alma de cazadory nunca me han gustado los Tartarines". Por último, D escola (1993: 19) califica de "tartarines de Puyo" a los mitomaníacos habitantes de este poblado frontera con la selva en la que iría a realizar su trabajo de campo con los achuar.

51 También un asceta etíope, a quien Leiris (5-VI-31) encontró en D akar, al comienzo de su viaje, al final del de aquel: "En el 'Hotel de los solteros' [...] encuentro de Kasa Makonnen, asceta abisinio llegado a D akar por Métamma,Jartum, Abécher, Fort-Lamy, N'G aunderé, D ouala, Chad. Ha viajado a pie durante tres años. Sin duda, corre detrás de una Verdad".

52 El exotismo como extrañamiento podía ser más fuerte para los propios nativos que, empleados por la Misión se alejaban de sus tierras, que paralos expedicionarios. Leiris (13-V-32) habla deuno de éstos, un senegalés que llegado a la frontera entre Sudán yEtiopía no puede más con su alma: "si la palabra 'exotismo' tiene algún sentido, es para él que debe tenerlo"; se daba como explicación a esto un texto tomado de la edición de 1929 del $\mathrm{N}$ otes and Q ueries de la RAI que hablaba de la incapacidad de adaptación de los miembros de las sociedades salvajes. 
53 Sin embargo, una fotografía de esta mezquita ilustraba hace algún tiempo las páginas del suplemento de viajes del periódico E 1 País como muestra de bello exotismo. Un manual de divulgación antropológica (Burenhult, 1998: 138) que también la presenta, lo hace con un pie de foto en la que se habla de los "antiguos centros de enseñanzas islámicas, como la Gran Mezquita de Y ené".

54 G riaule escribía a Rivière: "La mezquita de Yenné, esa perla de Sudán, ha sido construida bajo los planos de un arquitecto francés [... ]. Los indígenas están tan encantados con ella que todos los viernes el almani oficia en el emplazamiento de la antigua mezquita, destruida para que se construyese una escuela en estilo sudanés (5-XI-31)".

\section{Bibliografia}

ARMEL, A.

1997 Michel L eiris, Paris, Fayard.

AUSTER, P.

1999 Tombuctú, Barcelona, Anagrama.

BASTIDE, R.

1978 [1958] 0 Candombléda Bahia, São Paulo, Companhia Editora Nacional.

BEAUDOIR, G.

1984 Les D ogons du M ali, Paris, Armand Colin.

BLUMENSON, M.

1979 L e Réseau de résistance du M usée del'H omme. L es débuts de la Résistanœ en Franœ, Paris, Seuil.

BOUJOU, J.

1999 "Tutelle clientéliste, despotisme et Patrimonialisme: quelques figures de la chefferie dans les traditions orales dogons", Clio en A frique, n. 6. 
BRETON,A.

1969 [1952] Entretiens, Paris, Gallimard.

BRUMANA, F. G.

2002 Revista de A ntropologia E x perimental, n. 2.

CALAME-GRIAULE, G.

1987 [1965] E thnologie et langage. L a parole chez les D ogon, Paris, Institut d'E thnologie. CALTAGIRONE, B.

1988 "Le séjour en É thiopie de la mission Dakar-Djibuti", G radhiva, 5.

CIARCIA, G .

1998 'Ethnologues et 'dogon'. La fabrication d'un patrimoine ethnographique", G radhiva, 24.

CLIFFORD, J.

1983

"Power and Dialogue in Ethnography: Marcel Griaule's Initiation", Stocking, 1983.

1984 [1995] "Cuéntametu viaje: Michel Leiris", in D ilemas dela altura, Barcelona, G edisa. 1995 [1981] "Sobre el surrealismo etnográfico", in D ilemas dela altura, Barcelona, Gedisa. COGEZ, G.

1999a “O bjet cherché, accord perdu. Michel Leiris etl'Afrique”, L'H omme, 151. 1999b "Leiris sous influences", C ritique, 630.

COND OMINAS, G.

1991 [1975] L o ex ótio es otidiano, Barcelona, Júcar.

COPPO, P.

1998 L és guérisseurs de la folie. Histoires du plateau dogon, Le Plessis-Robinson, Institut Synthélabo pour le progrès de la connaissance.

DEL BOCA, A.

$1985 \quad$ H aile Selassie, Barcelona, O rbis. 
DELGADO, M.

1999 E l animal públion, Barcelona, Anagrama.

DESCOLA, P.

1993 L es lances du crépuscule. Relations Jivaros, haute A mazonie, Paris, Plon.

DIETERLEN, G.

1982 L e titre d'honneur des arou (D ogon, M ali), Paris, Mémoires de la Societé des Africanistes.

FABRE, D.

1997

"L'ethnologie française à la croisée des engagements (1940-1945)", in BO URSIER, J.-Y . (org.), Résistants et résistanœ, Paris, Harmattan.

1999 "Un rendez-vous manqué", L 'H omme, 151.

FOURNIER, M.

$1994 \quad$ M arcel M auss, Paris, Fayard.

FROBENIUS, L.

1938 El D ecamerón negro, Buenos Aires, Losada.

GANAY,A.ET AL

1987 E thnologiques. H omagges à M arœl G riaule, Paris, Hermann.

GEERTZ, C.

1989 E l antropólogo como autor, Barcelona, Paidós.

GIOBELLINA BRUMANA, F.

1999 "La escalera de Witgenstein o Cómo dejar de rompernos la cabeza con la eficacia simbólica", Revista de D ialectología y Tradiciones Populares, LIV, cuaderno segundo.

2000 "Artaud entre los tarahumara: una etnografía delirante", Cuadernos H ispanoamericanos, 603.

2001 “El etnólogo y sus fantasmas. Leiris en África”, R evista de D ialectología y Tradiciones Populares, LVI, cuaderno segundo. 
2002

"G riaule e a invenção de uma etnografia", Comunicação apresentada na XXVI Reunião da ANPOCS, Caxambu.

GRIAULE, M.

1983 [1938] Masques dogons, Paris, Institut d'Ethnologie.

GROSSI, M.

1999

"Nossa 'Chère Denise'. Entrevista com D enise Paulme”, Ilha. Revista de A ntropologia, n. 0.

2002 "G ermain Tillion, heroína da resistência", Comunicação apresentada na XXVI Reunião da ANPOCS, Caxambu.

HOLDER, G.

1998

"Esclaves et captifs au pays dogon. La société esclavagiste sama”, L 'H omme, 145.

HUET, J.-C.

1994

V illages perchés des dogon du M ali. H abitat, espace et société, Paris, L'Harmattan.

HUGON, A.

1998 L a gran aventura africana; ex ploradores y olonizadores, Barcelona, Ediciones B.

HUG UIER, F.

1990 Sur les traces de l'A frique Fantôme, Paris, Maeght.

JAMIN, J.

1996 "Introduction", in Miror de l'A frique, Paris, G allimard.

1999 “La part maudite de l'ethnographie”, L 'H omme, 151.

JAMIN, J. \& WILLIAMS, P.

2001 “Jazzanthropologie”, L’Homme, 158-159.

JOLLY, E.

1994

"D iffusion de trois cultes dans le sud du pays dogon: juru, ina y ara-monuna", Journal des africanistes, 64(2). 
1999 "Chefs sacrés et chefs de guerre dogon; deux pôles du povoir", Clio en A frique, 5.

LAURIËRE, C.

1999 "Paul Rivet, vie et oeuvre", G radhiva, 26.

LEACH, E.

1972 [1967] “Introducción”, in E structuralismo, mito y totemismo, Buenos Aires, Nueva Visión.

1975 [1969] "El método comparativo en antropología", in L a antropología como ciencia, Barcelona, Anagrama.

LEIRIS, M.

1948 L a langue secrètedes D ogons de Sanga, Paris, Institut d'E thnologie, Collection Travaux et Memoires de l'Institut d'E thnologie.

1968 "Préface", in METRAUX, A., L e vaudou haitien, Paris, G allimard.

1969 [1950] "L'Ethnographe devant le colonialisme", in C inq études d'ethnologie, Paris, Denoël/ G onthier.

1996 [1934] “Afrique fantôme”, in JAMIN, J. (ed.), M irors del'A frique, Paris, G allimard. LÉVI-STRAUSS, C.

1955 Tristes T ropiques, Paris, Plon.

LIBERSKI, D .

1989

"Pour une géographie de la saleté", Journal des africanistes, 59(1-2).

LIFCHITZ, D .

1933

“Ammulettes éthiopiennes", M inotaure, 2.

LIFCHITZ, D . \& PAULME, D .

1987 [1935] "Correspondencia de Deborah Lifchitz y D enise Paulme con Michel Leiris. Sanga 1935", G radhiva, 3. 
LOIZOS, P.

1997

Innovation in E thnographic Film. From innocenne to self-onsciousness, Chicago, The University of Chicago Press.

\section{LORD HAILEY}

1945 A n african survey. A study of problems arising in A frica south of the Sahara, Londres, Oxford University Press.

\section{MARTINELLI, B.}

$1999 \quad$ "Entre interdit et pardon. Le povoir des forgerons chez les Moose et les D ogon", Clio en A frique, 6.

MASSONET, S.

1997 "Du cinéma ethnographique et des prétendus rapports avec le surrealisme", G radhiva, 22.

MAUSS, M.

1950 [1902] "Esquisse d'une théorie générale de la magie", in Sociologieet anthropologie, Paris, PUF.

1969 [1913] "L'ethnographie en France et à l'étranger", in 0 euvres III, Paris, Minuit.

1969 [1920] "Etat actuel des sciences anthropologiques en France", in 0 euvres III, Paris, Minuit.

MAZON, B.

1985

"La fondation Rockefeller et les Sciences Sociales en France, 1925-1940", Revue F rançaise de Sodologie, 26(2).

PAULME, D.

1940 Organisation sociale des D ogon, Paris, D omat-Montchrestien.

PEIXOTO,F.

2000 D iálogos brasileiros. U ma análise da obra de Roger Bastide, São Paulo, Edusp/ Fapesp.

PETIT, V.

1998 Migrations et societé dogon, Paris, L'Harmattan. 
POUILLON, J.

1975 [1965] "Sartre y Lévi-Strauss. Analyse dialectique d'une relation dialectique analytique", in Fétiches sans fétichisme, Paris, Maspero.

PRICE, S. \& JAMIN, J.

1988

"Entretien avec Michel Leiris", G radhiva, 4.

RAILLÉ, M.

1894 L a Colonne Bonnier. Massacre de D ongoï (T acoubao), Reims, Imprimerie Coopérative.

RIVIÈRE, G. H.

1935

"Adieu au MET", Conferencia radiofónica, Archivos del Museo del Hombre, 2AM 1C8.

1987

"Témoinage", in Ganay, A., Lebeuf, A., Lebeuf, J.-P. \& Zahan, D., $\mathrm{E}$ thnologiques: $\mathrm{H}$ omagges à $\mathrm{M}$ arœl $\mathrm{G}$ riaule, Paris, Hermann.

ROUX, G.

1935 "Un grand seigneur abyssin: le Ras Haylou", Conferencia radiofónica, Archivos del Museo del Hombre, 2AM 1C8.

SEITÉ, Y.

1999 "L'âge du jazz", G radhiva, 25.

STAUDE, W.

1959 "Étude surla décoration picturale des Églises Abba Antonios de Gondar et D abbra Sina de Gorgora", A nnales d'É thiopie, 3.

STEPHEN, A.

1999 [1936] L a inocentada del acorazado, Madrid, Valdemar.

STOCKING, G.

$1983 \quad 0$ bservers 0 bserved: E ssays on E thnographic Fieldwork M adison, University of Wisconsin Press. 
Revista de Antro pologia, São Paulo, USP, 2002, v. 45 nํㅡ.

STOLLER, P.

1992

The cinematic griot. The ethnography of Jean Rouch, Chicago, The University of Chicago Press.

WALDBERG , P.

1970

"Au Fil du souvenir", in PO UILLO N, J. \& MARAND A, P., É changes et Communications. M élanges offerts à Claude L évi-Strauss à l'occasion de son 60 ème anniversaire, Haia/ Paris, Mouton.

ABST RACT: The D akar-D jibuti Mission, under Marcel Griaule's guidance, crossed the African continent between 1931 and 1933. This esay describes the links between the expedition and French ethnography at the moment of its birth, as well as the way the latter one was organized and developped.

KEY-WORD S: French ethnography, D ogon, Ethiopia.

Recebido em agosto de 2002. 